\title{
Design, Synthesis, and Acetylcholinesterase Inhibition Assay of Novel 9-(1-(Substituted-benzyl)piperidin-4-yl)- 2-chloro-9H-purin-6-amine Derivatives
}

\author{
Dongwei Kang, 1 Yu'ning Song, ${ }^{2}$ Peng Zhan,, Qingzhu Zhang, ${ }^{1}$ and Xinyong Liu ${ }^{1}$ \\ ${ }^{1}$ Department of Medicinal Chemistry, Key Laboratory of Chemical Biology (Ministry of Education), School of Pharmaceutical Sciences, \\ Shandong University, 44 West Culture Road, Jinan, Shandong 250012, China \\ ${ }^{2}$ Department of Pharmacology, Key Laboratory of Chemical Biology (Ministry of Education), School of Pharmaceutical Sciences, \\ Shandong University, 44 West Culture Road, Jinan, Shandong 250012, China
}

Correspondence should be addressed to Peng Zhan; zhanpeng1982@163.com and Xinyong Liu; xinyongllab@163.com

Received 22 May 2013; Revised 9 August 2013; Accepted 13 August 2013

Academic Editor: Marco Radi

Copyright (c) 2013 Dongwei Kang et al. This is an open access article distributed under the Creative Commons Attribution License, which permits unrestricted use, distribution, and reproduction in any medium, provided the original work is properly cited.

A new series of 9-(1-(substituted-benzyl)piperidin-4-yl)-2-chloro-9H-purin-6-amine derivatives were designed, synthesized, and characterized on the basis of ${ }^{1} \mathrm{H}-\mathrm{NMR},{ }^{13} \mathrm{C}-\mathrm{NMR}$, and mass spectra. The newly synthesized compounds were evaluated for the inhibition activity against acetylcholinesterase (AChE). Biological results revealed that four compounds among them showed moderate activities against AChE with inhibitory percentage more than $10 \%$ at $100 \mu \mathrm{M}$. Further pharmacology investigation towards other pathological routes in $\mathrm{AD}$ is currently underway.

\section{Introduction}

Since a cholinergic hypothesis has been postulated as a crucial element in Alzheimer's disease (AD) symptoms etiology, catalytic acetylcholinesterase (AChE) inhibitors have constituted until today the main drugs used against $\mathrm{AD}$ [1]. Reversible inhibition of brain AChE by anti-AD drugs such as tacrine [2], donepezil (Figure 1) [3], and huperzine [4] increases the AChE levels and improves neurotransmission in cholinergic synapses [5]. Since AChE plays a proaggregating (noncatalytic) role to accelerating $\beta$-amyloid peptide $(\mathrm{A} \beta)$ aggregation and deposition into the fibrils, inhibition of AChE is still the most successful therapeutic strategy for the symptomatic treatment of $\mathrm{AD}$ and its progression [6]. The search for novel AChE inhibitors with improved biological profiles continues to be of great interest to medicinal chemists.

In the past few years, a group of 2,4-disubstituted pyrimidine derivatives were reported as cholinesterase inhibitors and agents targeting multiple pathological routes in $\mathrm{AD}$. Particularly, compound PY-1 was identified as the lead candidate with a dual $\mathrm{ChE}\left(\mathrm{AChE} \mathrm{IC}_{50}=9.9 \mu \mathrm{M} ; \mathrm{BuChE}\right.$ $\left.\mathrm{IC}_{50}=11.4 \mu \mathrm{M}\right), \mathrm{A} \beta$-aggregation $(\mathrm{AChE}$-induced $=59.3 \%$; self-induced $=17.4 \%$ at $100 \mu \mathrm{M})$, and BACE-1 (34\% inhibition at $10 \mu \mathrm{M})$ inhibitory profile along with good cell viability $(81.0 \%$ neuroblastoma cell viability at $40 \mu \mathrm{M})[7-$ 10]. Meanwhile, $o$-fluorophenyl methyl derived triazole PU2012051296, effectively suppressed $A \beta$-induced neurotoxicity in hippocampal slice cultures. Importantly, the neuroprotective effect of compound PU2012051296 is comparable to those of flavopiridol and roscovitine, state of the art pharmaceuticals [11].

The refinement of the central core in bioactive molecules combined with introducing privileged substituents is a common practice in medicinal chemistry to find proprietary and novel hits. Based on the considerable similarities of these lead compounds, a fragment-based design was employed to identify alternative chemotypes (Figure 2). Meanwhile, in current drug research field, substituted purines have attracted considerable attention from the medicinal chemists in recent years, owing to the high number of positive hits encountered with this heterocycle. In this paper, a novel 


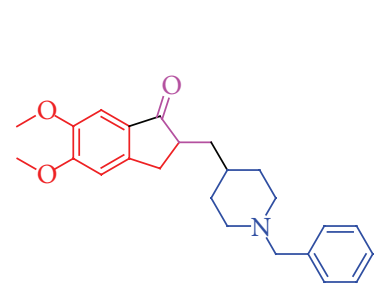

Donepezil

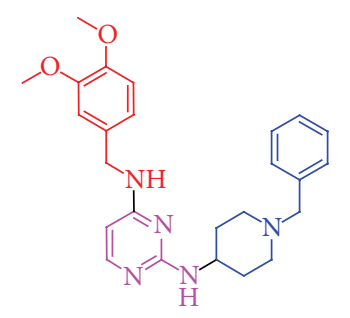

PY-1

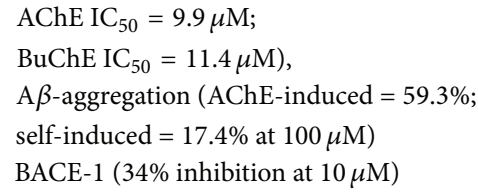

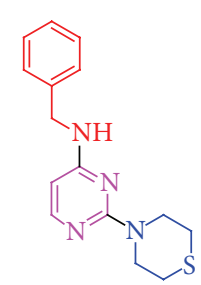

PY-2

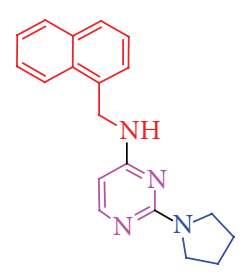

PY-3

$\mathrm{IC}_{50}=0.33 \mu \mathrm{M}(\mathrm{AChE}) ; \quad \mathrm{IC}_{50}=5.5 \mu \mathrm{M}(\mathrm{AChE})$; $2.30 \mu \mathrm{M}(\mathrm{BuChE})$.

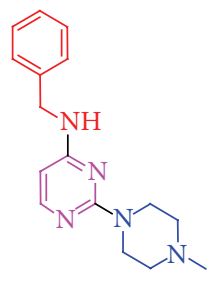

PY-4

$59 \%$ inhibition of hAChE-induced aggregation<smiles>Fc1ccccc1Cn1cc(Cn2cnc3c(NCc4ccccc4)nc(Cl)nc32)nn1</smiles>
of $\mathrm{A} \beta(1-40)$ fibrils (at $100 \mu \mathrm{M}$ ).

FIgURE 1: Structure of donepezil, 2,4-disubstituted pyrimidine AChE inhibitors, and purine derivative PU2012051296.<smiles>Fc1ccccc1Cn1cc(Cn2cnc3c(NCc4ccccc4)nc(Cl)nc32)nn1</smiles>

Lead compound PU2012051296<smiles>[Z17]CNc1nc(Cl)nc2c1ncn2C1CCN([R1])CC1</smiles>

Newly designed derivatives

FIGURE 2: The general structure formula of newly designed 9-(1-(substituted-benzyl)piperidin-4-yl)-2-chloro-9H-purin-6-amine derivatives.

series of 9-(1-(substituted-benzyl)piperidin-4-yl)-2-chloro9H-purin-6-amine derivatives were designed, synthesized, and evaluated for the inhibition activity against AChE.

\section{Results and Discussion}

2.1. Chemistry. The synthetic route of the target compounds is outlined in Scheme 1. which was started from commercially available materials and completed using well established methods. Initially, N-(3,4-dimethoxybenzyl)-2-chloro-9Hpurin-6-amine $(\mathbf{2 a})$ and $\mathrm{N}$-(benzo[d][1,3] dioxol-5-ylmethyl)-2-chloro-9H-purin-6-amine (2b) intermediates were synthesized from the starting material 2,6-dichloro-9Hpurine (1) by a nucleophilic aromatic substitution reaction at the C-6 position using either (3,4-dimethoxyphenyl) methanamine or benzo[d][1,3]dioxol-5-ylmethanamine in the presence of triethylamine (TEA). The reaction was run in $t$ - $\mathrm{BuOH}$ at $60^{\circ} \mathrm{C}$ for $30 \mathrm{~min}$. Intermediates 6 and 7 were obtained in good yields ranging (90.5\% and $89.7 \%)$
(Scheme 1) [7-10]. In the meantime, tert-butyl 4-hydroxypiperidine-1-carboxylate (4) was synthesized according to the reported procedure [12]. Then treatment of intermediate 4 with compound $\mathbf{2} \mathbf{a}$ or $\mathbf{2 b}$ in the presence of $\mathrm{NaH}$ afforded tert-butyl 4-(6-(3,4-dimethoxybenzylamino)-2-chloro9H-purin-9-yl)piperidine-1-carboxylate (5a) or tert-butyl 4-(6-(benzo[d] [1,3] dioxol-5-ylmethylamino)-2-chloro-9Hpurin-9-yl)piperidine-1-carboxylate $(5 \mathbf{b})$, respectively. The deprotection of the tert-butoxycarbonyl ( $t$-Boc) group of $5 \mathbf{a}$ and $\mathbf{5 b}$ was accomplished using trifluoroacetic acid (TFA) in dichloromethane (DCM) to yield N-(3,4-dimethoxybenzyl)2-chloro-9-(piperidin-4-yl)-9H-purin-6-amine (6a) and N(benzo[d][1,3]dioxol-5-ylmethyl)-2-chloro-9-(piperidin-4yl)-9H-purin-6-amine (6b), respectively, in good yield (91\% and $87 \%$ ). In the last step, the alkylation reaction of piperidine at $\mathrm{NH}$ position with various substituted benzyl chloride (bromine) afforded the target compounds. The newly synthesized compounds were characterized by physicochemical and spectral means, and the MS and NMR spectral 


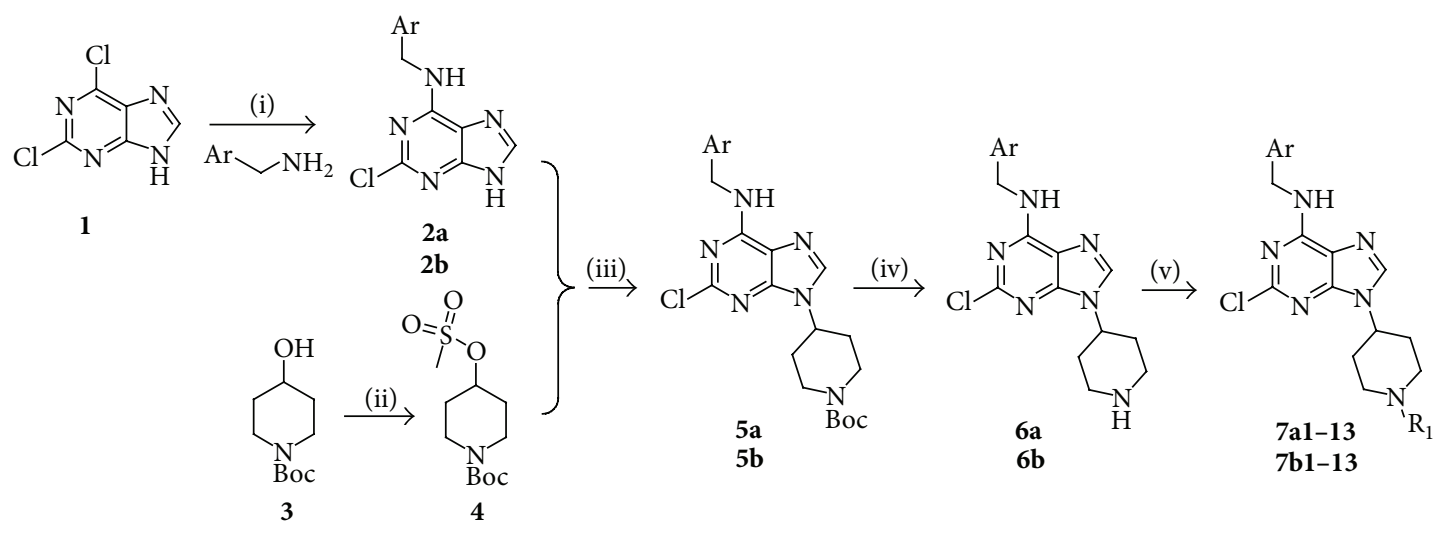

2a, 5a, 6a, 7a1-a13: Ar = 3,4-dimethoxyphenyl

2b, 5b, 6b, 7b1-b13: Ar = benzo[d][1,3]dioxol-5-yl

Scheme 1: Reagents and Conditions. (i) $t$ - $\mathrm{BuOH}, \mathrm{Et}_{3} \mathrm{~N}$; (ii): methanesulfonyl chloride ( $\mathrm{MsCl}$ ), $\mathrm{DCM}, \mathrm{Et}_{3} \mathrm{~N}$, and 4-DMAP; (iii) NaH, DMF; (iv): TFA, DCM; (v) substituted benzyl chloride (bromine, fluorine), DMF, and $\mathrm{K}_{2} \mathrm{CO}_{3}$.

data are found in agreement with the assigned molecular structures.

2.2. Cholinesterase Inhibition. All the newly synthesized compounds (7al-a13, 7b1-b13) were evaluated for their inhibitory activities toward AChE using an in vitro assay based on the reported protocol [7-10], in comparison with donepezil as standard drug. The anticholinesterase activities are summarized in Table 1 . Preliminary results in Table 1 revealed that compound $7 \mathbf{b} 9$ with a 3 -cyanobenzyl group in the benzo[d][1,3] dioxol-5-yl series displayed the highest AChE inhibitory activity $(15.42 \%$ at $100 \mu \mathrm{M})$ among all the tested compounds. Besides, compounds 7al, 7a7, and $7 \mathbf{b} 10$ with inhibitory percentage more than $10 \%$ at $100 \mu \mathrm{M}$ showed similar activities with compound $\mathbf{7 b} \mathbf{9}$ against AChE. Generally, all the compounds in both 3,4-dimethoxyphenyl and benzo[d][1,3]dioxol-5-yl series demonstrated much lower inhibitory activity toward AChE than the reference drug donepezil $(80.07 \%$ at $100 \mu \mathrm{M})$. Obviously, the activity of the compounds depends upon the nature of the substituents attached with purine ring. Even small modifications in every series can decrease and even lost their activity against AChE. Therefore, the coherent structure-activity relationship will be afforded by further pharmacology investigation, which is currently underway in our lab.

\section{Conclusion}

In summary, a novel series of 9-(1-(substituted-benzyl) piperidin-4-yl)-2-chloro-9H-purin-6-amine derivatives were designed and synthesized, and their AChE inhibitory activities were preliminary examined. Biological assay demonstrated that four compounds showed moderate activities against AChE with inhibitory percentage more than $10 \%$ at $100 \mu \mathrm{M}$. Further investigation of other bioactivities associated with $\mathrm{AD}$ of this series is ongoing work within our group and will be reported in due course.

\section{Experimental Section}

4.1. Chemistry. All melting points were determined on a micromelting point apparatus and are uncorrected. ${ }^{1} \mathrm{H}-\mathrm{NMR}$ and ${ }^{13} \mathrm{C}$-NMR spectra were obtained on a Bruker Avance- 400 NMR-spectrometer in the indicated solvents. Chemical shifts are expressed in $\delta$ units and TMS as internal reference. Mass spectra were taken on an LC Autosampler Device: Standard G1313A instrument. TLC was performed on Silica Gel GF254 for TLC (Merck) and spots were visualized by iodin evapours or by irradiation with UV light $(\lambda=254 \mathrm{~nm})$. Flash column chromatography was performed on column packed with Silica Gel60 (230-400 mesh). Solvents were reagent grade and when necessary were purified and dried by standard methods. Concentration of the reaction solutions involved the use of rotary evaporator at reduced pressure.

4.1.1. General Procedure for the Preparation of $\mathbf{2 a}$ and 2b. 2,6-Dichloro-9-H-purine $(1.89 \mathrm{~g}, 10 \mathrm{mmol})$ and $\mathrm{Et}_{3} \mathrm{~N}$ $(1.6 \mathrm{~mL}, 11 \mathrm{mmol})$ was dissolved in $t-\mathrm{BuOH}(50 \mathrm{~mL})$, and the mixed solution of 3,4-dimethoxybenzylamine $(1 \mathrm{a}, 1.50 \mathrm{~mL}$, $10 \mathrm{mmol})$ and $t-\mathrm{BuOH}(20 \mathrm{~mL})$ or benzo[d][1,3]dioxol-5ylmethanamine $(\mathbf{l b}, 1.27 \mathrm{~mL}, 10 \mathrm{mmol})$ and $t-\mathrm{BuOH}(20 \mathrm{~mL})$ was slowly added to the previous solution in $20 \mathrm{~min}$ at $60^{\circ} \mathrm{C}$. The resulting mixture was stirred at $60^{\circ} \mathrm{C}$ for $30 \mathrm{~min}$. Then the reaction mixture was poured into cold $\mathrm{H}_{2} \mathrm{O}(100 \mathrm{~mL})$, the resulting precipitate was collected by filtration underreduced pressure and washed sequentially with $\mathrm{H}_{2} \mathrm{O}$ then dried to give the corresponding product $\mathbf{2 a}$ as a white power with yield of $90.5 \%$ or $\mathbf{2} \mathbf{b}$ as a white power with yield of $89.7 \%$.

4.1.2. General Procedure for the Preparation of 4. N-Boc-4hydroxypiperidine $(3,8.05 \mathrm{~g}$, and $40 \mathrm{mmol})$ was dissolved in DCM $(50 \mathrm{~mL})$, then methanesulfonyl chloride $(3.4 \mathrm{~mL}$, $44 \mathrm{mmol}), \mathrm{Et}_{3} \mathrm{~N}(6.7 \mathrm{~mL}, 48 \mathrm{mmol})$ and 4 -DMAP $(0.05 \mathrm{~g}$, $4.0 \mathrm{mmol}$ ) were added to the above solution slowly in turn at $0^{\circ} \mathrm{C}$. The mixed solution of methanesulfonyl chloride $(3.4 \mathrm{~mL}$, 
TABLE 1: Cholinesterase inhibition activity of 9-(1-(substituted-benzyl)piperidin-4-yl)-2-chloro-9H-purin-6-amine derivatives ${ }^{\mathrm{a}}$.

\begin{tabular}{|c|c|c|c|}
\hline Compd. & $\mathrm{Ar}$ & $\mathrm{R}_{1}$ & Cholinesterase inhibition $\%$ at $100 \mu \mathrm{M}$ \\
\hline $7 \mathbf{a l}$ & 3,4-Dimethoxyphenyl & 3-Chlorobenzyl & 11.03 \\
\hline $7 \mathrm{a} 2$ & 3,4-Dimethoxyphenyl & 3-bromobenzyl & 0.24 \\
\hline $7 \mathbf{a} 3$ & 3,4-Dimethoxyphenyl & 4-Cyanobenzyl & 0.47 \\
\hline $7 \mathbf{a} 4$ & 3,4-Dimethoxyphenyl & 4-Nitrobenzyl & 3.84 \\
\hline $7 \mathbf{a 5}$ & 3,4-Dimethoxyphenyl & 3-Fluorobenzyl & 3.48 \\
\hline $7 \mathbf{a 6}$ & 3,4-Dimethoxyphenyl & Pyridine-4-yl-methyl & $\mathrm{NA}^{\mathrm{b}}$ \\
\hline $7 \mathrm{a} 7$ & 3,4-Dimethoxyphenyl & Benzyl & 14.57 \\
\hline $7 \mathrm{a} 8$ & 3,4-Dimethoxyphenyl & 4-Bromobenzyl & NA \\
\hline $7 a 9$ & 3,4-Dimethoxyphenyl & 3-Cyanobenzyl & 6.10 \\
\hline 7 a10 & 3,4-Dimethoxyphenyl & 4-Methoxybenzyl & NA \\
\hline 7al1 & 3,4-Dimethoxyphenyl & 2,6-Dicholobenzyl & NA \\
\hline $7 \mathrm{a} 12$ & 3,4-Dimethoxyphenyl & 2,4,6-Trimethylbenzyl & NA \\
\hline $7 \mathrm{a} 13$ & 3,4-Dimethoxyphenyl & 2-Fluorobenzyl & 4.02 \\
\hline $7 \mathrm{~b} \mathbf{1}$ & Benzo[d][1,3]dioxol-5-yl & 3-Chlorobenzyl & NA \\
\hline $7 \mathbf{b} 2$ & Benzo $[\mathrm{d}][1,3]$ dioxol-5-yl & 3-Bromobenzyl & 0.09 \\
\hline $7 \mathbf{b} 3$ & Benzo[d][1,3]dioxol-5-yl & 4-Cyanobenzyl & NA \\
\hline $7 \mathbf{b} 4$ & Benzo[d][1,3]dioxol-5-yl & 4-Nitrobenzyl & NA \\
\hline $7 \mathrm{~b} 5$ & Benzo[d][1,3]dioxol-5-yl & 3-Fluorobenzyl & 0.14 \\
\hline $7 \mathrm{~b} 6$ & Benzo[d][1,3]dioxol-5-yl & Pyridine-4-yl-methyl & NA \\
\hline $7 \mathrm{~b} 7$ & Benzo[d][1,3]dioxol-5-yl & Benzyl & 7.55 \\
\hline $7 \mathrm{~b} 8$ & Benzo $[\mathrm{d}][1,3]$ dioxol-5-yl & 4-Bromobenzyl & 7.29 \\
\hline $7 b 9$ & Benzo $[\mathrm{d}][1,3]$ dioxol-5-yl & 3-Cyanobenzyl & 15.42 \\
\hline $7 \mathrm{~b} 10$ & Benzo[d][1,3]dioxol-5-yl & 4-Methoxybenzyl & 11.21 \\
\hline $7 \mathrm{~b} 11$ & Benzo[d][1,3]dioxol-5-yl & 2,6-Dicholobenzyl & 3.80 \\
\hline $7 \mathrm{~b} 12$ & Benzo[d][1,3]dioxol-5-yl & 2,4,6-Trimethylbenzyl & 1.51 \\
\hline $7 b 13$ & Benzo[d][1,3]dioxol-5-yl & 2-Fluorobenzyl & 6.14 \\
\hline Donepezil & & & 80.07 \\
\hline
\end{tabular}

${ }^{a}$ See the experimental section for assay details. ${ }^{b}$ Not active.

$44 \mathrm{mmol})$ and DCM $(20 \mathrm{~mL})$ was slowly added to the mixed solution in $30 \mathrm{~min}$ at $60^{\circ} \mathrm{C}$. The mixtures were stirred at $0^{\circ} \mathrm{C}$ overnight. Then the reaction solution was alkalized to $\mathrm{PH}=9$ with $\mathrm{NaHCO}_{3}$. The solution was washed by water $(50 \mathrm{~mL})$ then extracted with DCM $(3 \times 15 \mathrm{~mL})$. Combined organic phase dried over anhydrous $\mathrm{Na}_{2} \mathrm{SO}_{4}$, filtered, and concentrated under reduced pressure to give the product 4 as white solid. Yield: $94.3 \%$.

4.1.3. General Procedure for the Preparation of $\mathbf{5 a}$ and $\mathbf{5} \boldsymbol{b}$. 2-Chloro- $N$-(3,4-dimethoxbenzyl)-9H-purin-6-amine(2a, $3.20 \mathrm{~g}, 10 \mathrm{mmol})$ or $N$-(benzo[d][1,3]dioxol-5-ylmethyl)2-chloro-9-(piperidin-4-yl)-9H-purin-6-amine(2b, 3.03 g, $10 \mathrm{mmol}$ ) was dissolved in DMF $(60 \mathrm{~mL})$ and added $60 \%$ dispersion $\mathrm{NaH}(0.48 \mathrm{~g}, 12 \mathrm{mmol})$ to the solution at room temperature. Then it slowly added the intermediate 4 (3.10 g,
$11 \mathrm{mmol}$ ) that dissolved in DMF $(20 \mathrm{~mL})$ to the previous mixed solution in $20 \mathrm{~min}$ at $60^{\circ} \mathrm{C}$. The reaction mixturewas rapid stirred at $100^{\circ} \mathrm{C}$ for $16 \mathrm{~h}$ (monitored by TLC). After removal of the solvent under reduced pressure, water $(30 \mathrm{~mL})$ was added and extracted with ethyl acetate $(3 \times$ $10 \mathrm{~mL}$ ). Combined organic phase was washed with brine and dried over anhydrous $\mathrm{Na}_{2} \mathrm{SO}_{4}$ to give the corresponding crude product, which was purified by flash column chromatography to afford compounds 5a as a pink crystal with yield of $31.5 \%$ or $\mathbf{5 b}$ as a pink crystal with yield of $29.7 \%$.

4.1.4. General Procedure for the Preparation of $\mathbf{6} \boldsymbol{a}$ and $\mathbf{6} \boldsymbol{b}$. To a solution of $5 \mathbf{a}(600 \mathrm{mg}, 1.19 \mathrm{mmol})$ or $5 \mathbf{b}(600 \mathrm{mg}, 1.23 \mathrm{mmol})$ in DCM $(20 \mathrm{~mL})$ TFA was added $(3 \mathrm{~mL})$ at room temperature and the solution was stirred for $5 \mathrm{~h}$. Then the reaction solution was alkalized to $\mathrm{PH}=9$ with $\mathrm{NaHCO}_{3}$. The solution was 
washed by water $(50 \mathrm{~mL})$ and then extracted with DCM (3 $\times 15 \mathrm{~mL}$ ). Combined organic phase dried over anhydrous $\mathrm{Na}_{2} \mathrm{SO}_{4}$, filtered and concentrated under reduced pressure to give the product $\mathbf{6 a}$ or $\mathbf{6 b}$.

2-Chloro-N-(3,4-dimethoxbenzyl)-9-(piperidin-4-yl)-9Hpurin-6-amine (6a). White crystal, yield $91 \%$, mp: $157-160^{\circ} \mathrm{C}$. ${ }^{1} \mathrm{H}$ NMR (400 MHz, DMSO-d6, ppm) $\delta: 8.73(1 \mathrm{H}, \mathrm{s})$, $8.25(1 \mathrm{H}, \mathrm{s}), 7.07(1 \mathrm{H}, \mathrm{s}), 6.87(2 \mathrm{H}, \mathrm{d}, J=4.04 \mathrm{~Hz}), 5.08(1 \mathrm{H}, \mathrm{s}$, $\mathrm{NH}), 4.55(2 \mathrm{H}, \mathrm{d}, J=5.36 \mathrm{~Hz}), 4.36\left(1 \mathrm{H}, \mathrm{dt}, J_{1}=10.80 \mathrm{~Hz}\right.$, $\left.J_{2}=5.12 \mathrm{~Hz}\right), 3.74\left(3 \mathrm{H}, \mathrm{s}, \mathrm{OCH}_{3}\right), 3.71\left(3 \mathrm{H}, \mathrm{s}, \mathrm{OCH}_{3}\right), 3.08$ $(2 \mathrm{H}, \mathrm{d}, J=8.88 \mathrm{~Hz}), 2.65\left(2 \mathrm{H}, \mathrm{dt}, J_{1}=14.28 \mathrm{~Hz}, J_{2}=3.52 \mathrm{~Hz}\right)$, 1.92-1.94 (4H, m) ${ }^{13} \mathrm{C}$ NMR (100 MHz, DMSO-d6, ppm) $\delta$ : $155.3,153.2,149.8,149.0,148.3,140.0,132.1,120.1,118.9,112.4$, $112.1,56.0,55.8,53.3,45.6$ (2C), 43.5, 33.0 (2C). ESI-MS: $m / z$ $403.5(\mathrm{M}+1), 405.5(\mathrm{M}+3), 525.3(\mathrm{M}+\mathrm{Na}) . \mathrm{C}_{19} \mathrm{H}_{23} \mathrm{ClN}_{6} \mathrm{O}_{2}$ (402.16).

$N$-(Benzo[d] [1,3]Dioxol-5-ylmethyl)-2-chloro-9-(piperidin-4$y$ l)-9H-purin-6-amine $(\mathbf{6} \boldsymbol{b})$. White crystal, yield 87\%, mp: 205-209 ${ }^{\circ}$ C. ${ }^{1} \mathrm{H}$ NMR (400 MHz, DMSO-d6, ppm) $\delta: 8.73$ $(1 \mathrm{H}, \mathrm{s}), 8.26(1 \mathrm{H}, \mathrm{s}), 6.93(1 \mathrm{H}, \mathrm{s}), 6.83(2 \mathrm{H}, \mathrm{d}, J=7.68 \mathrm{~Hz}), 5.97$ $\left(2 \mathrm{H}, \mathrm{s}, \mathrm{OCH}_{2} \mathrm{O}\right), 5.05(1 \mathrm{H}, \mathrm{s}, \mathrm{NH}), 4.54(2 \mathrm{H}, \mathrm{d}, J=4.92 \mathrm{~Hz})$, $4.35\left(1 \mathrm{H}, \mathrm{dt}, J_{1}=10.48 \mathrm{~Hz}, J_{2}=5.40 \mathrm{~Hz}\right), 3.05(2 \mathrm{H}, \mathrm{d}, J=$ $12.32 \mathrm{~Hz}), 2.60\left(2 \mathrm{H}, \mathrm{dt}, J_{1}=14.76 \mathrm{~Hz}, J_{2}=3.60 \mathrm{~Hz}\right), 1.96(4 \mathrm{H}$, $\left.\mathrm{dd}, J_{1}=16.64 \mathrm{~Hz}, J_{2}=2.80 \mathrm{~Hz}\right) .{ }^{13} \mathrm{C}$ NMR $(100 \mathrm{MHz}$, DMSOd6, ppm) $\delta: 155.3,153.2,149.9,147.6,146.6,140.1,133.7,121.1$, 118.9, 101.3, 55.3, 53.4, 45.7 (2C), 43.4, 33.2 (2C). ESI-MS: $m / z$ $387.3(\mathrm{M}+1), 389.3(\mathrm{M}+3), 409.4(\mathrm{M}+\mathrm{Na}) \cdot \mathrm{C}_{18} \mathrm{H}_{19} \mathrm{ClN}_{6} \mathrm{O}_{2}$ (386.13).

4.1.5. General Procedure for the Target Compounds $7 \boldsymbol{a}$ and $7 \boldsymbol{b}$. Compound $\mathbf{6 a}$ (or $\mathbf{6 b}$ ) was dissolved in anhydrous DMF $(10 \mathrm{~mL})$ in the presence of anhydrous $\mathrm{K}_{2} \mathrm{CO}_{3}$ (1.2 eq), followed by addition of appropriate substituted benzyl chloride (bromine, fluorine) (1.1 eq). The reaction mixture was stirred at room temperature overnight. The solvent was removed under reduced pressure, and then water $(20 \mathrm{~mL})$ was added. Extracted with ethyl acetate $(3 \times 10 \mathrm{~mL})$, and the organic phase was washed with saturated sodium chloride $(10 \mathrm{~mL})$ then dried over anhydrous $\mathrm{Na}_{2} \mathrm{SO}_{4}$ to give the corresponding crude product, which was purified by flash column chromatography to afford compounds 7a1-13 (or 7b1-13).

2-Chloro-9-(1-(3-chlorobenzyl)piperidin-4-yl)-N-(3,4-dimethoxbenzyl)-9H-purin-6-amine (7a1). Recrystallized from $\mathrm{EA} / \mathrm{PE}$ as a white crystal, yield $62.3 \%, \mathrm{mp}: 176-180^{\circ} \mathrm{C} .{ }^{1} \mathrm{H}$ NMR $(400 \mathrm{MHz}$, DMSO-d6, ppm) $\delta: 8.30(1 \mathrm{H}, \mathrm{s}), 7.29-7.39$ $(4 \mathrm{H}, \mathrm{m}), 7.06(1 \mathrm{H}, \mathrm{s}), 6.86(2 \mathrm{H}, \mathrm{d}, J=4.32 \mathrm{~Hz}), 5.07(1 \mathrm{H}, \mathrm{s}$, $\mathrm{NH}), 4.55(2 \mathrm{H}, \mathrm{d}, J=7.24 \mathrm{~Hz}), 4.30\left(1 \mathrm{H}, \mathrm{dt}, J_{1}=8.32 \mathrm{~Hz}, J_{2}\right.$ $=3.27 \mathrm{~Hz}), 3.73\left(3 \mathrm{H}, \mathrm{s}, \mathrm{OCH}_{3}\right), 3.71\left(3 \mathrm{H}, \mathrm{s}, \mathrm{OCH}_{3}\right), 3.54(2 \mathrm{H}$, s), $2.92(2 \mathrm{H}, \mathrm{d}, J=7.80 \mathrm{~Hz}), 2.11-2.19(4 \mathrm{H}, \mathrm{m}), 1.93(2 \mathrm{H}, \mathrm{d}, J$ $=8.80 \mathrm{~Hz}) .{ }^{13} \mathrm{C}$ NMR $(100 \mathrm{MHz}$, DMSO-d6, ppm) $\delta: 155.3$, 153.2, 150.0, 149.0, 148.3, 141.7, 140.1, 133.4, 132.2, 130.5, 128.9, $127.9,127.4,120.1,118.9,112.5,112.2,61.4,56.0,55.9,52.9,52.5$ (2C), 43.5, 31.9 (2C). ESI-MS: $m / z 527.3(\mathrm{M}+1), 529.2(\mathrm{M}+$ 3), $549.3(\mathrm{M}+\mathrm{Na}) \cdot \mathrm{C}_{26} \mathrm{H}_{28} \mathrm{Cl}_{2} \mathrm{~N}_{6} \mathrm{O}_{2}(526.17)$.

2-Chloro-9-(1-(3-bromobenzyl)piperidin-4-yl)-N-(3,4-dimethoxbenzyl)-9H-purin-6-amine (7a2). Recrystallized from
EA/PE as a white crystal, yield $57.2 \%, \mathrm{mp}: 187-190^{\circ} \mathrm{C} .{ }^{1} \mathrm{H}$ NMR (400 MHz, DMSO-d6, ppm) $\delta: 8.31(1 \mathrm{H}, \mathrm{s}), 7.61(1 \mathrm{H}, \mathrm{dd}$, $\left.J_{1}=7.96, J_{2}=1.0 \mathrm{~Hz}\right), 7.52\left(1 \mathrm{H}, \mathrm{dd}, J_{1}=7.64 \mathrm{~Hz}, J_{2}=1.52 \mathrm{~Hz}\right)$, $7.40\left(1 \mathrm{H}, \mathrm{dt}, J_{1}=7.48 \mathrm{~Hz}, J_{2}=1.0 \mathrm{~Hz}\right), 7.23\left(1 \mathrm{H}, \mathrm{dt}, J_{1}=7.76 \mathrm{~Hz}\right.$, $\left.J_{2}=1.68 \mathrm{~Hz}\right), 7.06(1 \mathrm{H}, \mathrm{s}), 6.86(2 \mathrm{H}, \mathrm{d}, J=8.26 \mathrm{~Hz}), 5.07(1 \mathrm{H}$, $\mathrm{s}, \mathrm{NH}), 4.54(2 \mathrm{H}, \mathrm{d}, J=5.44 \mathrm{~Hz}), 4.34\left(1 \mathrm{H}, \mathrm{dt}, J_{1}=11.72 \mathrm{~Hz}\right.$, $\left.J_{2}=3.84 \mathrm{~Hz}\right), 3.73\left(3 \mathrm{H}, \mathrm{s}, \mathrm{OCH}_{3}\right), 3.71\left(3 \mathrm{H}, \mathrm{s}, \mathrm{OCH}_{3}\right), 3.60$ $(2 \mathrm{H}, \mathrm{s}), 2.96(2 \mathrm{H}, \mathrm{d}, J=11.52 \mathrm{~Hz}), 2.27(2 \mathrm{H}, \mathrm{t}, J=11.68 \mathrm{~Hz})$, $2.08-2.17(2 \mathrm{H}, \mathrm{m}), 1.95-1.99(2 \mathrm{H}, \mathrm{d}, J=7.28 \mathrm{~Hz}) .{ }^{13} \mathrm{C}$ NMR (100 MHz, DMSO-d6, ppm) $\delta: 155.3,153.2,150.0,149.0,148.3$, $140.0,138.0,133.0,132.2,131.3,129.4,128.0,124.4,120.1,119.0$, 112.5, 112.2, 61.4, 56.0, 55.9, 52.8, 52.7 (2C), 43.5, 31.9 (2C). ESI-MS: $m / z 573.2(\mathrm{M}+3), 574.4(\mathrm{M}+4), 576.2(\mathrm{M}+6)$. $\mathrm{C}_{26} \mathrm{H}_{28} \mathrm{BrClN}_{6} \mathrm{O}_{2}(570.11)$.

2-Chloro-9-(1-(4-cyanobenzyl)piperidin-4-yl)-N-(3,4-dimethoxbenzyl)-9H-purin-6-amine (7a3). Recrystallized from EA/PE as a white crystal, yield $66.5 \%, \mathrm{mp}: 193-196^{\circ} \mathrm{C} .{ }^{1} \mathrm{H}$ NMR $(400 \mathrm{MHz}$, DMSO-d6, ppm) $\delta: 8.30(1 \mathrm{H}, \mathrm{s}), 7.82(2 \mathrm{H}$, $\mathrm{d}, J=4.10 \mathrm{~Hz}), 7.54(2 \mathrm{H}, \mathrm{d}, J=4.08 \mathrm{~Hz}), 7.06(1 \mathrm{H}, \mathrm{s}), 6.87(2 \mathrm{H}$, dd, $\left.J_{1}=8.64 \mathrm{~Hz}, J_{2}=3.26 \mathrm{~Hz}\right), 5.07(1 \mathrm{H}, \mathrm{s}, \mathrm{NH}), 4.54(2 \mathrm{H}$, d, $J=5.20 \mathrm{~Hz}), 4.32\left(1 \mathrm{H}, \mathrm{dt}, J_{1}=8.62 \mathrm{~Hz}, J_{2}=3.56 \mathrm{~Hz}\right), 3.74$ $\left(3 \mathrm{H}, \mathrm{s}, \mathrm{OCH}_{3}\right), 3.71\left(3 \mathrm{H}, \mathrm{s}, \mathrm{OCH}_{3}\right), 3.62(2 \mathrm{H}, \mathrm{s}), 2.90(2 \mathrm{H}$, d, $J=9.28 \mathrm{~Hz}), 2.17\left(4 \mathrm{H}, \mathrm{dd}, J_{1}=16.60, J_{2}=8.88 \mathrm{~Hz}\right), 1.95$ $(2 \mathrm{H}, \mathrm{d}, J=11.56 \mathrm{~Hz}) .{ }^{13} \mathrm{C}$ NMR $(100 \mathrm{MHz}$, DMSO-d6, ppm) $\delta: 155.3,153.2,149.9,149.0,148.3,145.1,140.1,132.6$ (2C), 132.1, 130.0 (2C), 120.1, 119.3, 118.9, 112.4, 112.1, 110.2, 61.6, 56.0, 55.8, 52.8, 52.6 (2C), 43.5, 31.8 (2C). ESI-MS: $m / z 518.4(\mathrm{M}+1)$, $540.4(\mathrm{M}+\mathrm{Na}) \cdot \mathrm{C}_{27} \mathrm{H}_{28} \mathrm{ClN}_{7} \mathrm{O}_{2}(517.20)$.

2-Chloro-9-(1-(4-nitrobenzyl)piperidin-4-yl)-N-(3,4-dimethoxbenzyl)-9H-purin-6-amine (7a4). Recrystallized from EA/PE as a yellow crystal, yield: $53.4 \%, \mathrm{mp}: 209-212^{\circ} \mathrm{C} .{ }^{1} \mathrm{H}$ NMR (400 MHz, DMSO-d6, ppm) $\delta: 8.29(1 \mathrm{H}, \mathrm{s}), 8.21(2 \mathrm{H}$, $\mathrm{d}, J=8.12 \mathrm{~Hz}), 7.62(2 \mathrm{H}, \mathrm{d}, J=8.08 \mathrm{~Hz}), 7.06(1 \mathrm{H}, \mathrm{s}), 6.89(2 \mathrm{H}$, $\mathrm{d}, J=4.68 \mathrm{~Hz}), 5.07(1 \mathrm{H}, \mathrm{s}, \mathrm{NH}), 4.55(2 \mathrm{H}, \mathrm{d}, J=6.32 \mathrm{~Hz}), 4.32$ $\left(1 \mathrm{H}, \mathrm{dt}, J_{1}=11.32, J_{2}=3.28 \mathrm{~Hz}\right), 3.74\left(3 \mathrm{H}, \mathrm{s}, \mathrm{OCH}_{3}\right), 3.71(3 \mathrm{H}$, $\left.\mathrm{s}, \mathrm{OCH}_{3}\right), 3.67(2 \mathrm{H}, \mathrm{s}), 2.92(2 \mathrm{H}, \mathrm{t}, J=9.08 \mathrm{~Hz}), 2.14-2.25(4 \mathrm{H}$, m), $1.97(2 \mathrm{H}, \mathrm{d}, J=4.58 \mathrm{~Hz}) .{ }^{13} \mathrm{C}$ NMR $(100 \mathrm{MHz}$, DMSO-d6, ppm) $\delta: 155.3,153.2,150.0,149.0,148.3,147.3,147.1,140.1,132.1$, 130.2 (2C), 124.0 (2C), 120.1, 118.9, 112.4, 112.1, 61.3, 56.0, 55.8, 52.8, $52.6(2 \mathrm{C}), 43.5,31.8(2 \mathrm{C})$. ESI-MS: $m / z 538.4(\mathrm{M}+1)$, $540.4(\mathrm{M}+3), 560.3(\mathrm{M}+\mathrm{Na}) . \mathrm{C}_{26} \mathrm{H}_{28} \mathrm{ClN}_{7} \mathrm{O}_{4}(537.19)$.

2-Chloro-9-(1-(3-fluorobenzyl)piperidin-4-yl)-N-(3,4-dimethoxbenzyl)-9H-purin-6-amine (7a5). Recrystallized from EA/PE as a white crystal, yield: $49.7 \%, \mathrm{mp}: 183-185^{\circ} \mathrm{C} .{ }^{1} \mathrm{H}$ NMR $(400 \mathrm{MHz}$, DMSO-d6, ppm) $\delta: 8.30(1 \mathrm{H}, \mathrm{s}), 7.38(1 \mathrm{H}$, dt, $\left.J_{1}=8.04 \mathrm{~Hz}, J_{2}=6.16 \mathrm{~Hz}\right), 7.17\left(2 \mathrm{H}, \mathrm{dd}, J_{1}=9.36 \mathrm{~Hz}, J_{2}\right.$ $=6.28 \mathrm{~Hz}), 7.09(2 \mathrm{H}, \mathrm{s}), 6.87(2 \mathrm{H}, \mathrm{d}, J=3.26 \mathrm{~Hz}), 5.07(1 \mathrm{H}, \mathrm{s}$, $\mathrm{NH}), 4.55(2 \mathrm{H}, \mathrm{d}, J=5.56 \mathrm{~Hz}), 4.31\left(1 \mathrm{H}, \mathrm{dt}, J_{1}=10.28 \mathrm{~Hz}, J_{2}\right.$ $=3.68 \mathrm{~Hz}), 3.74\left(3 \mathrm{H}, \mathrm{s}, \mathrm{OCH}_{3}\right), 3.71\left(3 \mathrm{H}, \mathrm{s}, \mathrm{OCH}_{3}\right), 3.55(2 \mathrm{H}$, s), $2.93(2 \mathrm{H}, \mathrm{d}, J=7.16 \mathrm{~Hz}), 2.11-2.17(4 \mathrm{H}, \mathrm{m}), 1.93(2 \mathrm{H}, \mathrm{d}, J$ $=8.88 \mathrm{~Hz}) \cdot{ }^{13} \mathrm{C}$ NMR $(100 \mathrm{MHz}$, DMSO-d6, ppm) $\delta: 163.9$, $161.5,155.3,153.2,149.9,149.0,148.3,142.0,140.0,132.1,130.5$, $125.2,120.1,118.9,115.7,114.3,112.4,61.5,56.0,55.8,52.8,52.5$ (2C), 43.5, $31.8(2 \mathrm{C})$. ESI-MS: $m / z 511.5(\mathrm{M}+1), 513.4(\mathrm{M}+3)$, $515.4(\mathrm{M}+5), 533.3(\mathrm{M}+\mathrm{Na}) . \mathrm{C}_{26} \mathrm{H}_{28} \mathrm{ClFN}_{6} \mathrm{O}_{2}(510.19)$. 
2-Chloro-9-(1-(pyridine-4-yl-methyl)piperidin-4-yl)-N-(3,4dimethoxbenzyl)-9H-purin-6-amine (7a6). Recrystallized from EA/PE as a yellow crystal, yield: $61.2 \%, \mathrm{mp}: 158-161^{\circ} \mathrm{C}$. ${ }^{1} \mathrm{H}$ NMR (400 MHz, DMSO-d6, ppm) $\delta: 8.53$ (2H, dd, $J_{1}=$ $\left.4.56 \mathrm{~Hz}, J_{2}=1.36 \mathrm{~Hz}\right), 8.30(1 \mathrm{H}, \mathrm{s}), 7.35(2 \mathrm{H}, \mathrm{d}, J=5.80 \mathrm{~Hz})$, $7.06(1 \mathrm{H}, \mathrm{s}), 6.86(2 \mathrm{H}, \mathrm{d}, J=2.28 \mathrm{~Hz}), 5.06(1 \mathrm{H}, \mathrm{s}, \mathrm{NH}), 4.53$ $(2 \mathrm{H}, \mathrm{d}, J=5.44 \mathrm{~Hz}), 4.32\left(1 \mathrm{H}, \mathrm{dt}, J_{1}=7.28 \mathrm{~Hz}, J_{2}=3.76 \mathrm{~Hz}\right)$, $3.73\left(3 \mathrm{H}, \mathrm{s}, \mathrm{OCH}_{3}\right), 3.70\left(3 \mathrm{H}, \mathrm{s}, \mathrm{OCH}_{3}\right), 3.57(2 \mathrm{H}, \mathrm{s}), 2.92$ $(2 \mathrm{H}, \mathrm{d}, J=9.40 \mathrm{~Hz}), 2.13-2.20(4 \mathrm{H}, \mathrm{m}), 1.94(2 \mathrm{H}, \mathrm{d}, J=$ $11.2 \mathrm{~Hz}) .{ }^{13} \mathrm{C}$ NMR $(100 \mathrm{MHz}$, DMSO-d6, ppm) $\delta: 155.3$, $153.2,150.3$ (2C), 149.0, 148.3, 148.0, 140.1, 132.2, 124.2 (2C), $120.2,119.3,118.9,112.5,112.2,60.9,56.0,55.9,52.7,52.6(2 \mathrm{C})$, 43.5, 31.8 (2C). ESI-MS: $m / z 494.4(\mathrm{M}+1), 496.4(\mathrm{M}+3)$, $516.5(\mathrm{M}+\mathrm{Na}) \cdot \mathrm{C}_{25} \mathrm{H}_{28} \mathrm{ClN}_{7} \mathrm{O}_{2}(493.20)$.

2-Chloro-9-(1-benzylpiperidin-4-yl)-N-(3,4-dimethoxbenzyl)9H-purin-6-amine (7a7). Recrystallized from EA/PE as a white crystal, yield: $55.7 \%, \mathrm{mp}:{ }^{179-182^{\circ} \mathrm{C} .}{ }^{1} \mathrm{H}$ NMR (400 MHz, DMSO-d6, ppm) $\delta: 8.29(1 \mathrm{H}, \mathrm{s}), 7.33(4 \mathrm{H}, \mathrm{t}, J=$ $4.68 \mathrm{~Hz}), 7.27(1 \mathrm{H}, \mathrm{t}, J=4.24 \mathrm{~Hz}), 7.06(1 \mathrm{H}, \mathrm{s}), 6.87(2 \mathrm{H}, \mathrm{d}, J=$ $5.06 \mathrm{~Hz}), 5.07(1 \mathrm{H}, \mathrm{s}, \mathrm{NH}), 4.55(2 \mathrm{H}, \mathrm{d}, J=5.16 \mathrm{~Hz}), 4.31(1 \mathrm{H}$, $\left.\mathrm{dt}, J_{1}=9.26 \mathrm{~Hz}, J_{2}=4.04 \mathrm{~Hz}\right), 3.73\left(3 \mathrm{H}, \mathrm{s}, \mathrm{OCH}_{3}\right), 3.70(3 \mathrm{H}, \mathrm{s}$, $\left.\mathrm{OCH}_{3}\right), 3.52(2 \mathrm{H}, \mathrm{s}), 2.93(2 \mathrm{H}, \mathrm{d}, J=6.24 \mathrm{~Hz}), 2.12-2.14(4 \mathrm{H}$, $\mathrm{m}), 1.94(2 \mathrm{H}, \mathrm{d}, J=6.43 \mathrm{~Hz}) .{ }^{13} \mathrm{C}$ NMR $(100 \mathrm{MHz}, \mathrm{DMSO}-\mathrm{d} 6$, ppm) $\delta: 155.3,153.2,150.0,149.0,148.3,140.1,138.9,132.1$, 129.3(2C), 128.7(2C), 127.4, 120.1, 118.9, 112.3, 112.1, 62.3, 56.0, 55.8, 52.9, 52.6 (2C), 43.5, 31.8 (2C). ESI-MS: $m / z 493.4(\mathrm{M}+$ 1), $495.3(\mathrm{M}+3), 515.4(\mathrm{M}+\mathrm{Na}) \cdot \mathrm{C}_{26} \mathrm{H}_{29} \mathrm{ClN}_{6} \mathrm{O}_{2}(492.20)$.

2-Chloro-9-(1-(4-bromobenzyl)piperidin-4-yl)-N-(3,4-dimethoxbenzyl)-9H-purin-6-amine (7a8). Recrystallized from EA/PE as a white crystal, yield $52.5 \%, \mathrm{mp}: 209-212{ }^{\circ} \mathrm{C} .{ }^{1} \mathrm{H}$ NMR (400 MHz, DMSO-d6, ppm) $\delta: 8.30(1 \mathrm{H}, \mathrm{s}), 7.52(2 \mathrm{H}$, d, $J=1.60 \mathrm{~Hz}), 7.29(2 \mathrm{H}, \mathrm{d}, J=8.36 \mathrm{~Hz}), 7.07(1 \mathrm{H}, \mathrm{s}), 6.87(2 \mathrm{H}$, $\mathrm{d}, J=4.38 \mathrm{~Hz}), 5.07(1 \mathrm{H}, \mathrm{s}, \mathrm{NH}), 4.55(2 \mathrm{H}, \mathrm{d}, J=5.76 \mathrm{~Hz})$, $4.29\left(1 \mathrm{H}, \mathrm{dt}, J_{1}=8.37 \mathrm{~Hz}, J_{2}=5.76 \mathrm{~Hz}\right), 3.74\left(3 \mathrm{H}, \mathrm{s}, \mathrm{OCH}_{3}\right)$, $3.71\left(3 \mathrm{H}, \mathrm{s}, \mathrm{OCH}_{3}\right), 3.49(2 \mathrm{H}, \mathrm{s}), 2.91(2 \mathrm{H}, \mathrm{d}, J=6.36 \mathrm{~Hz})$, 1.99-2.14 (4H, m), $1.93(2 \mathrm{H}, \mathrm{d}, J=6.24 \mathrm{~Hz}) .{ }^{13} \mathrm{C} \mathrm{NMR}$ (100 MHz, DMSO-d6, ppm) $\delta: 155.3,153.2,150.0,149.0,148.3$, $140.1,138.4,132.1,131.5$ (2C), 131.4 (2C), 120.4, 120.1, 118.9, $112.4,112.1,61.4,56.0,55.8,52.8,52.5(2 \mathrm{C}), 43.5,31.8(2 \mathrm{C})$. ESIMS: $m / z 571.3(\mathrm{M}+1), 573.2(\mathrm{M}+3), 575.3(\mathrm{M}+5), 595.3(\mathrm{M}$ $+\mathrm{Na}) \cdot \mathrm{C}_{26} \mathrm{H}_{28} \mathrm{BrClN}_{6} \mathrm{O}_{2}$ (570.11).

2-Chloro-9-(1-(3-cyanobenzyl)piperidin-4-yl)-N-(3,4-dimethoxbenzyl)-9H-purin-6-amine (7a9). Recrystallized from EA/PE as a white crystal, yield $62.1 \%, \mathrm{mp}: 209-210^{\circ} \mathrm{C} .{ }^{1} \mathrm{H}$ NMR (400 MHz, DMSO-d6, ppm) $\delta: 8.30(1 \mathrm{H}, \mathrm{s}), 7.77(1 \mathrm{H}$, $\left.\mathrm{dd}, J_{1}=25.48 \mathrm{~Hz}, J_{2}=7.60 \mathrm{~Hz}\right), 7.68(2 \mathrm{H}, \mathrm{d}, J=7.80 \mathrm{~Hz}), 7.56$ $(1 \mathrm{H}, \mathrm{t}, J=7.68 \mathrm{~Hz}), 7.06(1 \mathrm{H}, \mathrm{s}), 6.87(2 \mathrm{H}, \mathrm{d}, J=9.84 \mathrm{~Hz}), 5.07$ $(1 \mathrm{H}, \mathrm{s}, \mathrm{NH}), 4.55(2 \mathrm{H}, \mathrm{d}, J=5.16 \mathrm{~Hz}), 4.33\left(1 \mathrm{H}, \mathrm{dt}, J_{1}=10.84, J_{2}\right.$ $=3.26 \mathrm{~Hz}), 3.73\left(3 \mathrm{H}, \mathrm{s}, \mathrm{OCH}_{3}\right), 3.71\left(3 \mathrm{H}, \mathrm{s}, \mathrm{OCH}_{3}\right), 3.59(2 \mathrm{H}$, s), $2.93(2 \mathrm{H}, \mathrm{d}, J=9.16 \mathrm{~Hz}), 2.11-2.18(4 \mathrm{H}, \mathrm{m}), 1.93(2 \mathrm{H}, \mathrm{d}, J=$ $12.80 \mathrm{~Hz}) .{ }^{13} \mathrm{C}$ NMR $(100 \mathrm{MHz}, \mathrm{DMSO}-\mathrm{d} 6, \mathrm{ppm}) \delta: 155.3$, $153.2,150.0,149.0,148.3,140.8,140.1,134.1,132.6,132.1,131.3$, $129.9,120.1,119.4,118.9,112.4,111.7,61.1,56.0,55.8,52.7,52.5$ (2C), 43.5, 31.8 (2C). ESI-MS: $m / z 518.4(\mathrm{M}+1), 520.3(\mathrm{M}+$ 3), $522.6(\mathrm{M}+5), 540.3(\mathrm{M}+\mathrm{Na}) \cdot \mathrm{C}_{27} \mathrm{H}_{28} \mathrm{ClN}_{7} \mathrm{O}_{2}(517 \cdot 20)$.
2-Chloro-9-(1-(4-methoxybenzyl)piperidin-4-yl)-N-(3,4dimethoxbenzyl)-9H-purin-6-amine (7a10). Recrystallized from EA/PE as a white crystal, yield $56.3 \%$, mp: $202-205^{\circ} \mathrm{C}$. ${ }^{1} \mathrm{H}$ NMR (400 MHz, DMSO-d6, ppm) $\delta: 8.28$ (1H, s), 7.24 $(2 \mathrm{H}, \mathrm{d}, J=8.56 \mathrm{~Hz}), 7.06(1 \mathrm{H}, \mathrm{s}), 6.90(2 \mathrm{H}, \mathrm{d}, J=8.60 \mathrm{~Hz})$, $6.86(2 \mathrm{H}, \mathrm{d}, J=4.56 \mathrm{~Hz}), 5.07(1 \mathrm{H}, \mathrm{s}, \mathrm{NH}), 4.54(2 \mathrm{H}, \mathrm{d}, J=$ $5.48 \mathrm{~Hz}), 4.27\left(1 \mathrm{H}, \mathrm{dt}, J_{1}=8.62 \mathrm{~Hz}, J_{2}=3.64 \mathrm{~Hz}\right), 3.74(3 \mathrm{H}, \mathrm{s}$, $\left.\mathrm{OCH}_{3}\right), 3.73\left(3 \mathrm{H}, \mathrm{s}, \mathrm{OCH}_{3}\right), 3.70(3 \mathrm{H}, \mathrm{s}), 3.44(2 \mathrm{H}, \mathrm{s}), 2.92$ $(2 \mathrm{H}, \mathrm{d}, J=6.32 \mathrm{~Hz}), 2.07-2.09(4 \mathrm{H}, \mathrm{m}), 1.92(2 \mathrm{H}, \mathrm{s}) .{ }^{13} \mathrm{C}$ NMR (100 MHz, DMSO-d6, ppm) $\delta: 158.8,155.3,153.2,149.9$, $149.0,148.3,140.1,132.1,130.6,130.5$ (2C), 120.1, 118.9, 114.0 (2C), 112.4, 112.1, 61.7, 56.0, 55.8, 55.5, 53.0, 52.4 (2C), 43.5, 31.8 (2C). ESI-MS: $m / z 523.5(\mathrm{M}+1), 525.4(\mathrm{M}+3), 545.3(\mathrm{M}$ $+\mathrm{Na}) . \mathrm{C}_{27} \mathrm{H}_{31} \mathrm{ClN}_{6} \mathrm{O}_{3}(522.21)$.

2-Chloro-9-(1-(2,6-dicholobenzyl)piperidin-4-yl)-N-(3,4dimethoxbenzyl)-9H-purin-6-amine (7a11). Recrystallized from EA/PE as a white crystal, yield 58.3\%, mp: $196-198^{\circ} \mathrm{C}$. ${ }^{1} \mathrm{H}$ NMR (400 MHz, DMSO-d6, ppm) $\delta: 8.28$ (1H, s), 7.34 $\left(2 \mathrm{H}, \mathrm{dt}, J_{1}=17.22 \mathrm{~Hz}, J_{2}=7.20 \mathrm{~Hz}\right), 7.34\left(1 \mathrm{H}, \mathrm{dd}, J_{1}=8.56 \mathrm{~Hz}\right.$, $\left.J_{2}=7.48 \mathrm{~Hz}\right), 7.06(1 \mathrm{H}, \mathrm{s}), 6.86(2 \mathrm{H}, \mathrm{d}, J=3.82 \mathrm{~Hz}), 5.06(1 \mathrm{H}$, $\mathrm{s}, \mathrm{NH}), 4.55(2 \mathrm{H}, \mathrm{d}, J=4.56 \mathrm{~Hz}), 4.29\left(1 \mathrm{H}, \mathrm{dt}, J_{1}=10.26, J_{2}=\right.$ $4.32 \mathrm{~Hz}), 3.74\left(3 \mathrm{H}, \mathrm{s}, \mathrm{OCH}_{3}\right), 3.72(2 \mathrm{H}, \mathrm{s}), 3.70\left(3 \mathrm{H}, \mathrm{s}, \mathrm{OCH}_{3}\right)$, $2.93(2 \mathrm{H}, \mathrm{d}, J=11.68 \mathrm{~Hz}), 2.40\left(2 \mathrm{H}, \mathrm{dt}, J_{1}=9.92 \mathrm{~Hz}, J_{2}=\right.$ $1.80 \mathrm{~Hz}), 1.93-2.06(4 \mathrm{H}, \mathrm{m}) .{ }^{13} \mathrm{C}$ NMR (100 MHz, DMSO-d6, ppm) $\delta: 155.3,153.2,150.0,149.0,148.3,140.1,136.5(2 \mathrm{C}), 134.3$, $132.0,130.4,129.2$ (2C), 120.1, 118.9, 112.4, 112.1, 62.3, 56.3, 56.0, 55.8, 52.5 (2C), 43.2, 31.8 (2C). ESI-MS: $m / z 561.2(\mathrm{M}+$ 1), $563.2(\mathrm{M}+3), 565.3(\mathrm{M}+5) \cdot \mathrm{C}_{26} \mathrm{H}_{27} \mathrm{Cl}_{3} \mathrm{~N}_{6} \mathrm{O}_{2}$ (560.13).

2-Chloro-9-(1-(2,4,6-trimethylbenzyl)piperidin-4-yl)-N-(3,4dimethoxbenzyl)-9H-purin-6-amine (7a12). Recrystallized from EA/PE as a white crystal, yield: $63.3 \%, \mathrm{mp}: 203-206^{\circ} \mathrm{C}$. ${ }^{1} \mathrm{H}$ NMR (400 MHz, DMSO-d6, ppm) $\delta: 8.27(1 \mathrm{H}, \mathrm{s}), 7.06$ $(1 \mathrm{H}, \mathrm{s}), 6.86(2 \mathrm{H}, \mathrm{s}), 6.80(2 \mathrm{H}, \mathrm{s}), 5.07(1 \mathrm{H}, \mathrm{s}, \mathrm{NH}), 4.54(2 \mathrm{H}$, $\mathrm{d}, J=5.48 \mathrm{~Hz}), 4.40\left(1 \mathrm{H}, \mathrm{dt}, J_{1}=11.24 \mathrm{~Hz}, J_{2}=5.48 \mathrm{~Hz}\right)$, $3.73\left(3 \mathrm{H}, \mathrm{s}, \mathrm{OCH}_{3}\right), 3.70\left(3 \mathrm{H}, \mathrm{s}, \mathrm{OCH}_{3}\right), 3.43(2 \mathrm{H}, \mathrm{s}), 2.86$ $(2 \mathrm{H}, \mathrm{d}, J=11.4 \mathrm{~Hz}), 2.32-2.33(6 \mathrm{H}, \mathrm{m}), 2.19-2.21(5 \mathrm{H}, \mathrm{m})$, 1.92-1.94 (4H, m). ${ }^{13} \mathrm{C}$ NMR (100 MHz, DMSO-d6, ppm) $\delta: 155.3,153.2,149.9,149.0,148.3,139.9,137.9(2 \mathrm{C}), 136.0,132.2$, 132.1, 129.1 (2C), 120.1, 118.9, 112.4, 112.1, 56.0, 55.8, 55.4, 53.0, 52.3 (2C), 43.5, 32.1 (2C), 21.0, 20.2 (2C). ESI-MS: $m / z 535.3$ $(\mathrm{M}+1), 537.4(\mathrm{M}+3) \cdot \mathrm{C}_{29} \mathrm{H}_{35} \mathrm{ClN}_{6} \mathrm{O}_{2}(534.25)$.

2-Chloro-9-(1-(2-fluorobenzyl)piperidin-4-yl)-N-(3,4-dimethoxbenzyl)-9H-purin-6-amine (7a13). Recrystallized from EA/PE as a white crystal, yield $54.3 \%, \mathrm{mp}: 188-192^{\circ} \mathrm{C} .{ }^{1} \mathrm{H}$ NMR (400 MHz, DMSO-d6, ppm) $\delta: 8.27(1 \mathrm{H}, \mathrm{s}), 7.44(1 \mathrm{H}$, $\left.\mathrm{dt}, J_{1}=8.04 \mathrm{~Hz}, J_{2}=1.80 \mathrm{~Hz}\right), 7.34\left(1 \mathrm{H}, \mathrm{dt}, J_{1}=5.48 \mathrm{~Hz}, J_{2}=\right.$ $1.72 \mathrm{~Hz}), 7.15-7.22(2 \mathrm{H}, \mathrm{m}), 7.06(1 \mathrm{H}, \mathrm{s}), 6.86(2 \mathrm{H}, \mathrm{d}, J=$ $4.32 \mathrm{~Hz}), 5.07(1 \mathrm{H}, \mathrm{s}, \mathrm{NH}), 4.55(2 \mathrm{H}, \mathrm{d}, J=4.96 \mathrm{~Hz}), 4.29(1 \mathrm{H}$, $\left.\mathrm{dt}, J_{1}=11.26 \mathrm{~Hz}, J_{2}=7.40 \mathrm{~Hz}\right), 3.73\left(3 \mathrm{H}, \mathrm{s}, \mathrm{OCH}_{3}\right), 3.71(3 \mathrm{H}, \mathrm{s}$, $\left.\mathrm{OCH}_{3}\right), 3.58(2 \mathrm{H}, \mathrm{s}), 2.95(2 \mathrm{H}, \mathrm{d}, J=10.52 \mathrm{~Hz}), 2.09-2.22(4 \mathrm{H}$, $\mathrm{m}), 1.93(2 \mathrm{H}, \mathrm{d}, J=8.28 \mathrm{~Hz}) .{ }^{13} \mathrm{C}$ NMR $(100 \mathrm{MHz}, \mathrm{DMSO}-$ d6, ppm) $\delta: 162.5,160.1,155.3,153.2,149.9,149.0,148.3,140.1$, 132.1, 129.6, 125.1, 124.6, 120.1, 118.9, 115.7, 115.5, 112.3, 56.0, 55.8, 54.9, 52.8, $52.4(2 \mathrm{C}), 43.5,31.8$ (2C). ESI-MS: $m / z 511.4(\mathrm{M}+$ 1), $513.4(\mathrm{M}+3), 533.3(\mathrm{M}+\mathrm{Na}) \cdot \mathrm{C}_{26} \mathrm{H}_{28} \mathrm{ClFN}_{6} \mathrm{O}_{2}$ (510.19). 
N-(Benzo[d][1,3]dioxol-5-ylmethyl)-2-chloro-9-(1-(3-chlorobenzyl)piperidin-4-yl)-9H-purin-6-amine (7b1). Recrystallized from EA/PE as a white crystal, yield 55.9\%, mp: 146$150^{\circ} \mathrm{C} .{ }^{1} \mathrm{H}$ NMR $(400 \mathrm{MHz}, \mathrm{DMSO}-\mathrm{d} 6, \mathrm{ppm}) \delta: 8.32(1 \mathrm{H}, \mathrm{s})$, $7.38(1 \mathrm{H}, \mathrm{d}, J=10.44 \mathrm{~Hz}), 7.33(3 \mathrm{H}, \mathrm{dd}, J=9.96 \mathrm{~Hz}, 8.28 \mathrm{~Hz})$, $6.93(1 \mathrm{H}, \mathrm{s}), 6.83\left(2 \mathrm{H}, \mathrm{dd}, J_{1}=8.38 \mathrm{~Hz}, J_{2}=2.83 \mathrm{~Hz}\right), 5.96$ $\left(2 \mathrm{H}, \mathrm{s}, \mathrm{OCH}_{2} \mathrm{O}\right), 5.04(1 \mathrm{H}, \mathrm{s}, \mathrm{NH}), 4.53(2 \mathrm{H}, \mathrm{d}, J=5.20 \mathrm{~Hz})$, $4.32\left(1 \mathrm{H}, \mathrm{dt}, J_{1}=9.24, J_{2}=3.64 \mathrm{~Hz}\right), 3.54(2 \mathrm{H}, \mathrm{s}), 2.92(2 \mathrm{H}, \mathrm{d}$, $J=7.92 \mathrm{~Hz}), 2.15(4 \mathrm{H}, \mathrm{t}, J=9.72 \mathrm{~Hz}), 1.96(2 \mathrm{H}, \mathrm{t}, J=8.88 \mathrm{~Hz})$. ${ }^{13} \mathrm{C}$ NMR (100 MHz, DMSO-d6, ppm) $\delta: 155.3,153.2,150.0$, 147.6, 146.6, 141.5, 140.0, 133.6, 133.4, 130.5, 128.9, 127.9, 127.4, 126.7, 121.1, 118.9, 108.5, 101.3, 61.4, 52.8, 52.5 (2C), 43.4, 31.8 (2C). ESI-MS: $m / z 511.3(\mathrm{M}+1), 513.4(\mathrm{M}+3), 533.2(\mathrm{M}+$ Na). $\mathrm{C}_{25} \mathrm{H}_{24} \mathrm{Cl}_{2} \mathrm{~N}_{6} \mathrm{O}_{2}$ (510.13).

$N$-(Benzo[d][1,3]dioxol-5-ylmethyl)-2-chloro-9-(1-(3-bromobenzyl)piperidin-4-yl)-9H-purin-6-amine (7b2). Recrystallized from EA/PE as a white crystal, yield 62.1\%, mp: 174$178^{\circ} \mathrm{C} .{ }^{1} \mathrm{H}$ NMR $(400 \mathrm{MHz}$, DMSO-d6, ppm) $\delta: 8.31(1 \mathrm{H}, \mathrm{s})$, $7.61(1 \mathrm{H}, \mathrm{d}, J=7.92 \mathrm{~Hz}), 7.52(1 \mathrm{H}, \mathrm{d}, J=7.48 \mathrm{~Hz}), 7.39(1 \mathrm{H}, \mathrm{t}$, $J=7.36 \mathrm{~Hz}), 7.21(1 \mathrm{H}, \mathrm{t}, J=7.44 \mathrm{~Hz}), 6.92(1 \mathrm{H}, \mathrm{s}), 6.83(2 \mathrm{H}$, dd, $\left.J_{1}=12.16, J_{2}=4.28 \mathrm{~Hz}\right), 5.97\left(2 \mathrm{H}, \mathrm{s}, \mathrm{OCH}_{2} \mathrm{O}\right), 5.04(1 \mathrm{H}$, $\mathrm{s}, \mathrm{NH}), 4.53(2 \mathrm{H}, \mathrm{d}, J=5.28 \mathrm{~Hz}), 4.32\left(1 \mathrm{H}, \mathrm{dt}, J_{1}=7.92 \mathrm{~Hz}, J_{2}\right.$ $=4.48 \mathrm{~Hz}), 3.61(2 \mathrm{H}, \mathrm{s}), 2.96(2 \mathrm{H}, \mathrm{d}, J=11.40 \mathrm{~Hz}), 2.27(2 \mathrm{H}, \mathrm{t}$, $J=11.44 \mathrm{~Hz}), 2.14\left(2 \mathrm{H}, \mathrm{dd}, J_{1}=21.84 \mathrm{~Hz}, J_{2}=11.72 \mathrm{~Hz}\right), 1.96$ $(2 \mathrm{H}, \mathrm{d}, J=10.24 \mathrm{~Hz}) .{ }^{13} \mathrm{C}$ NMR $(100 \mathrm{MHz}$, DMSO-d6, ppm) $\delta: 155.2,153.2,150.0,147.6,146.6,140.1,137.9,133.6,133.0,131.3$, $129.4,128.1,124.4,121.1,120.3,118.9,108.5,101.3,61.4,55.3,52.6$ (2C), 43.4, $31.8(2 \mathrm{C})$. ESI-MS: $m / z 555.2(\mathrm{M}+1), 558.2(\mathrm{M}+$ 4), $579.1(\mathrm{M}+\mathrm{Na}) \cdot \mathrm{C}_{25} \mathrm{H}_{24} \mathrm{BrClN}_{6} \mathrm{O}_{2}$ (554.08).

$\mathrm{N}$-(Benzo[d][1,3] dioxol-5-ylmethyl)-2-chloro-9-(1-(4-cyanobenzyl)piperidin-4-yl)-9H-purin-6-amine (7b3). Recrystallized from EA/PE as a white crystal, yield 58.4\%, mp: 221$225^{\circ} \mathrm{C} .{ }^{1} \mathrm{H}$ NMR $(400 \mathrm{MHz}, \mathrm{DMSO}-\mathrm{d} 6, \mathrm{ppm}) \delta: 8.30(1 \mathrm{H}$, s), $7.80(2 \mathrm{H}, \mathrm{d}, J=8.04 \mathrm{~Hz}), 7.54(2 \mathrm{H}, \mathrm{d}, J=8.06 \mathrm{~Hz}), 6.83$ $\left(2 \mathrm{H}, \mathrm{dd}, J_{1}=10.88 \mathrm{~Hz}, J_{2}=7.84 \mathrm{~Hz}\right), 6.93(1 \mathrm{H}, \mathrm{s}), 5.97(2 \mathrm{H}, \mathrm{s}$, $\left.-\mathrm{OCH}_{2} \mathrm{O}-\right), 5.03(1 \mathrm{H}, \mathrm{s}, \mathrm{NH}), 4.53(2 \mathrm{H}, \mathrm{d}, J=4.68 \mathrm{~Hz}), 4.32$ $\left(1 \mathrm{H}, \mathrm{dt}, J_{1}=10.88 \mathrm{~Hz}, J_{2}=4.26 \mathrm{~Hz}\right), 3.62(2 \mathrm{H}, \mathrm{s}), 2.92(2 \mathrm{H}, \mathrm{d}, J$ $=9.20 \mathrm{~Hz}), 2.17(4 \mathrm{H}, \mathrm{t}, J=9.44 \mathrm{~Hz}), 1.97(2 \mathrm{H}, \mathrm{t}, J=11.60 \mathrm{~Hz})$. ${ }^{13} \mathrm{C}$ NMR (100 MHz, DMSO-d6, ppm) $\delta: 155.3,153.2,150.0$, $147.6,146.6,145.1,143.2,140.1,133.6$ (2C), 132.6, 130.0 (2C), $128.4,121.1,119.4,110.2,108.5,101.3,65.9,61.6,52.5$ (2C), 43.3, 31.8 (2C). ESI-MS: $m / z 502.3(\mathrm{M}+1), 504.3(\mathrm{M}+3), 506.3(\mathrm{M}$ + 5), $524.4(\mathrm{M}+\mathrm{Na}) \cdot \mathrm{C}_{26} \mathrm{H}_{24} \mathrm{ClN}_{7} \mathrm{O}_{2}$ (501.17).

$\mathrm{N}$-(Benzo[d][1,3]dioxol-5-ylmethyl)-2-chloro-9-(1-(4-nitrobenzyl)piperidin-4-yl)-9H-purin-6-amine (7b4). Recrystallized from EA/PE as a yellow crystal, yield 49.5\%, mp: $137-$ $141^{\circ} \mathrm{C} .{ }^{1} \mathrm{H}$ NMR $(400 \mathrm{MHz}, \mathrm{DMSO}-\mathrm{d} 6, \mathrm{ppm}) \delta: 8.30(1 \mathrm{H}, \mathrm{s})$, $8.22\left(2 \mathrm{H}, \mathrm{dd}, J_{1}=7.08 \mathrm{~Hz}, J_{2}=1.68 \mathrm{~Hz}\right), 7.62(2 \mathrm{H}, \mathrm{d}, J=$ $8.68 \mathrm{~Hz}), 6.92(1 \mathrm{H}, \mathrm{s}), 6.83\left(2 \mathrm{H}, \mathrm{dd}, J_{1}=8.38 \mathrm{~Hz}, J_{2}=2.83 \mathrm{~Hz}\right)$, $5.96\left(2 \mathrm{H}, \mathrm{s},-\mathrm{OCH}_{2} \mathrm{O}-\right), 5.04(1 \mathrm{H}, \mathrm{s}, \mathrm{NH}), 4.53(2 \mathrm{H}, \mathrm{d}, J=$ $5.20 \mathrm{~Hz}), 4.32\left(1 \mathrm{H}, \mathrm{dt}, J_{1}=11.40, J_{2}=3.88 \mathrm{~Hz}\right), 3.67(2 \mathrm{H}, \mathrm{s})$, $2.93(2 \mathrm{H}, \mathrm{d}, J=10.44 \mathrm{~Hz}), 2.17(4 \mathrm{H}, \mathrm{t}, J=10.44 \mathrm{~Hz}), 1.96(2 \mathrm{H}$, $\mathrm{t}, J=3.84 \mathrm{~Hz}) .{ }^{13} \mathrm{C}$ NMR $(100 \mathrm{MHz}$, DMSO-d6, ppm) $\delta: 155.2$, 153.2, 149.7, 147.6, 147.3, 147.1, 146.6, 140.2, 133.6, 130.2 (2C), 128.6, 124.1 (2C), 121.1, 118.9, 108.5, 101.3, 61.3, 52.8, 52.6 (2C),
43.3, 31.8 (2C). ESI-MS: $m / z 522.3(\mathrm{M}+1), 524.4(\mathrm{M}+3)$, $544.4(\mathrm{M}+\mathrm{Na}) . \mathrm{C}_{25} \mathrm{H}_{24} \mathrm{ClN}_{7} \mathrm{O}_{4}(521.16)$.

$\mathrm{N}$-(Benzo[d][1,3] dioxol-5-ylmethyl)-2-chloro-9-(1-(3-fluorobenzyl)piperidin-4-yl)-9H-purin-6-amine (7b5). Recrystallized from EA/PE as a white crystal, yield 64.1\%, mp: 144$148^{\circ} \mathrm{C} .{ }^{1} \mathrm{H}$ NMR $(400 \mathrm{MHz}, \mathrm{DMSO}-\mathrm{d} 6, \mathrm{ppm}) \delta: 8.31(1 \mathrm{H}, \mathrm{s})$, $7.38\left(1 \mathrm{H}, \mathrm{dt}, J_{1}=8.04 \mathrm{~Hz}, J_{2}=6.48 \mathrm{~Hz}\right), 7.17\left(2 \mathrm{H}, \mathrm{dt}, J_{1}=\right.$ $\left.7.96 \mathrm{~Hz}, J_{2}=2.12 \mathrm{~Hz}\right), 7.08\left(1 \mathrm{H}, \mathrm{dt}, J_{1}=8.64 \mathrm{~Hz}, J_{2}=2.23 \mathrm{~Hz}\right)$, $6.93(1 \mathrm{H}, \mathrm{s}), 6.83(2 \mathrm{H}, \mathrm{t}, J=7.72 \mathrm{~Hz}), 5.97\left(2 \mathrm{H}, \mathrm{s},-\mathrm{OCH}_{2} \mathrm{O}-\right.$ ), $5.05(1 \mathrm{H}, \mathrm{s}, \mathrm{NH}), 4.54(2 \mathrm{H}, \mathrm{d}, J=5.72 \mathrm{~Hz}), 4.32(1 \mathrm{H}, \mathrm{dt}$, $\left.J_{1}=7.24 \mathrm{~Hz}, J_{2}=4.26 \mathrm{~Hz}\right), 3.55(2 \mathrm{H}, \mathrm{s}), 2.93(2 \mathrm{H}, \mathrm{d}, J=$ $6.92 \mathrm{~Hz}), 2.16(4 \mathrm{H}, \mathrm{t}, J=8.96 \mathrm{~Hz}), 1.94(2 \mathrm{H}, \mathrm{d}, J=7.72 \mathrm{~Hz})$. ${ }^{13} \mathrm{C}$ NMR (400 MHz, DMSO-d6, ppm) $\delta: 163.9,161.5,155.3$, 153.2, 150.0, 147.6, 146.6, 142.1, 140.1, 133.6, 130.6, 125.1, 121.1, 118.9, 115.7, 114.2, 108.5, 101.2, 61.5, 52.8, 52.5 (2C), 43.4, 31.8 (2C). ESI-MS: $m / z 495.3(\mathrm{M}+1), 497.4(\mathrm{M}+3), 517.4(\mathrm{M}+$ Na). $\mathrm{C}_{25} \mathrm{H}_{24} \mathrm{ClFN}_{6} \mathrm{O}_{2}$ (494.16).

$N-(B e n z o[d][1,3]$ dioxol-5-ylmethyl)-2-chloro-9-(1-(pyridine4-yl-methyl)piperidin-4-yl)-9H-purin-6-amine (7b6). Recrystallized from EA/PE as a yellow crystal, yield: $62.3 \%$, mp: $154-157^{\circ} \mathrm{C} .{ }^{1} \mathrm{H}$ NMR $(400 \mathrm{MHz}$, DMSO-d6, ppm) $\delta: 8.53$ $\left(2 \mathrm{H}, \mathrm{dd}, J_{1}=4.48 \mathrm{~Hz}, J_{2}=1.44 \mathrm{~Hz}\right), 8.31(1 \mathrm{H}, \mathrm{s}), 7.35(2 \mathrm{H}, \mathrm{d}$, $J=5.84 \mathrm{~Hz}), 6.92(1 \mathrm{H}, \mathrm{s}), 6.83\left(2 \mathrm{H}, \mathrm{dd}, J_{1}=10.12 \mathrm{~Hz}, J_{2}=\right.$ $7.80 \mathrm{~Hz}), 5.97\left(2 \mathrm{H}, \mathrm{s},-\mathrm{OCH}_{2} \mathrm{O}-\right), 5.04(1 \mathrm{H}, \mathrm{s}, \mathrm{NH}), 4.53(2 \mathrm{H}$, $\mathrm{d}, J=5.76 \mathrm{~Hz}), 4.32\left(1 \mathrm{H}, \mathrm{dt}, J_{1}=10.48 \mathrm{~Hz}, J_{2}=3.62 \mathrm{~Hz}\right), 3.57$ $(2 \mathrm{H}, \mathrm{s}), 2.93(2 \mathrm{H}, \mathrm{d}, J=9.20 \mathrm{~Hz}), 2.17(4 \mathrm{H}, \mathrm{t}, J=12.16 \mathrm{~Hz})$, $1.95(2 \mathrm{H}, \mathrm{d}, J=10.64 \mathrm{~Hz}) .{ }^{13} \mathrm{C}$ NMR $(100 \mathrm{MHz}$, DMSO-d6, ppm) $\delta: 155.2,153.2,150.0$ (2C), 148.0, 147.6, 147.0, 146.6, 140.1, 133.6, 124.2 (2C), 121.1, 120.3, 118.9, 108.5, 101.3, 60.9, 52.6, 49.1 (2C), 43.4, 31.8 (2C). ESI-MS: $m / z 478.3(\mathrm{M}+1), 480.3(\mathrm{M}+$ 3), $482.4(\mathrm{M}+5), 500.2(\mathrm{M}+\mathrm{Na}) \cdot \mathrm{C}_{24} \mathrm{H}_{24} \mathrm{ClN}_{7} \mathrm{O}_{2}$ (477.17).

N-(Benzo[d][1,3]dioxol-5-ylmethyl)-2-chloro-9-(1-benzylpiperidin-4-yl)-9H-purin-6-amine (7b7). Recrystallized from $\mathrm{EA} / \mathrm{PE}$ as a white crystal, yield $58.5 \%$, mp: $169-172^{\circ} \mathrm{C} .{ }^{1} \mathrm{H}$ NMR $(400 \mathrm{MHz}, \mathrm{DMSO}-\mathrm{d} 6, \mathrm{ppm}) \delta: 8.30(1 \mathrm{H}, \mathrm{s}), 7.33(4 \mathrm{H}$, $\mathrm{t}, J=4.60 \mathrm{~Hz}), 7.25\left(1 \mathrm{H}, \mathrm{dd}, J_{1}=8.52 \mathrm{~Hz}, J_{2}=4.28 \mathrm{~Hz}\right), 6.92$ $(1 \mathrm{H}, \mathrm{s}), 6.83\left(2 \mathrm{H}, \mathrm{dd}, J_{1}=10.0 \mathrm{~Hz}, J_{2}=7.80 \mathrm{~Hz}\right), 5.96(2 \mathrm{H}, \mathrm{s}$, $\left.-\mathrm{OCH}_{2} \mathrm{O}-\right), 5.04(1 \mathrm{H}, \mathrm{s}, \mathrm{NH}), 4.52(2 \mathrm{H}, \mathrm{d}, J=5.68 \mathrm{~Hz}), 4.29$ $\left(1 \mathrm{H}, \mathrm{dt}, J_{1}=7.81, J_{2}=3.88 \mathrm{~Hz}\right), 3.52(2 \mathrm{H}, \mathrm{s}), 2.92(2 \mathrm{H}, \mathrm{d}, J=$ $6.36 \mathrm{~Hz}), 2.13\left(4 \mathrm{H}, \mathrm{dt}, J_{1}=11.36, J_{2}=7.40 \mathrm{~Hz}\right), 1.94(2 \mathrm{H}, \mathrm{s})$. ${ }^{13} \mathrm{C}$ NMR (100 MHz, DMSO-d6, ppm) $\delta: 155.2,153.1,150.0$, 147.6, 146.6, 140.2, 138.9, 133.6, 129.3 (2C), 128.6 (2C), 127.4, $121.1,120.3,118.9,108.5,101.3,62.3,52.9,52.6(2 \mathrm{C}), 43.4,31.8$ (2C). ESI-MS: $m / z 477.3(\mathrm{M}+1), 479.3(\mathrm{M}+3), 581.4(\mathrm{M}+5)$, $599.3(\mathrm{M}+\mathrm{Na}) \cdot \mathrm{C}_{25} \mathrm{H}_{25} \mathrm{ClN}_{6} \mathrm{O}_{2}$ (476.17).

$N$-(Benzo[d][1,3]dioxol-5-ylmethyl)-2-chloro-9-(1-(4-bromobenzyl)piperidin-4-yl)-9H-purin-6-amine (7b8). Recrystallized from EA/PE as a white crystal, yield 54.3\%, mp: 204$208^{\circ} \mathrm{C} .{ }^{1} \mathrm{H}$ NMR $(400 \mathrm{MHz}, \mathrm{DMSO}-\mathrm{d} 6, \mathrm{ppm}) \delta: 8.30(1 \mathrm{H}, \mathrm{s})$, $7.54(2 \mathrm{H}, \mathrm{d}, J=1.60 \mathrm{~Hz}), 7.28(2 \mathrm{H}, \mathrm{d}, J=8.32 \mathrm{~Hz}), 6.93(1 \mathrm{H}$, s), $6.83\left(2 \mathrm{H}, \mathrm{dd}, J_{1}=7.26 \mathrm{~Hz}, J_{2}=1.84 \mathrm{~Hz}\right), 5.97(2 \mathrm{H}, \mathrm{s},-$ $\left.\mathrm{OCH}_{2} \mathrm{O}-\right), 5.04(1 \mathrm{H}, \mathrm{s}, \mathrm{NH}), 4.54(2 \mathrm{H}, \mathrm{d}, J=5.80 \mathrm{~Hz}), 4.30$ $\left(1 \mathrm{H}, \mathrm{dt}, J_{1}=7.28 \mathrm{~Hz}, J_{2}=4.28 \mathrm{~Hz}\right), 3.50(2 \mathrm{H}, \mathrm{s}), 2.92(2 \mathrm{H}, \mathrm{d}, J=$ $6.6 \mathrm{~Hz}), 2.20\left(4 \mathrm{H}, \mathrm{dt}, J_{1}=12.36, J_{2}=8.60 \mathrm{~Hz}\right), 1.94(2 \mathrm{H}, \mathrm{s}) .{ }^{13} \mathrm{C}$ NMR (100 MHz, DMSO-d6, ppm) $\delta: 155.2,153.2,150.0,147.6$, 146.7, 140.2, 138.4, 133.6, 131.5 (2C), 131.4 (2C), 121.1, 120.9, 
120.4, 118.9, 108.5, 101.2, 61.4, 52.9, 52.5 (2C), 43.4, 31.8 (2C). ESI-MS: $m / z 557.1(\mathrm{M}+3), 559.1(\mathrm{M}+5) . \mathrm{C}_{25} \mathrm{H}_{24} \mathrm{BrClN}_{6} \mathrm{O}_{2}$ (554.08).

$N$-(Benzo $[d][1,3]$ dioxol-5-ylmethyl)-2-chloro-9-(1-(3-cyanobenzyl)piperidin-4-yl)-9H-purin-6-amine (7b9). Recrystallized from EA/PE as a white crystal, yield 48.4\%, mp: $200-$ $204^{\circ} \mathrm{C} .{ }^{1} \mathrm{H}$ NMR $(400 \mathrm{MHz}, \mathrm{DMSO}-\mathrm{d} 6, \mathrm{ppm}) \delta: 8.31(1 \mathrm{H}, \mathrm{s})$, $7.76\left(1 \mathrm{H}, \mathrm{dd}, J_{1}=10.84 \mathrm{~Hz}, J_{2}=7.64 \mathrm{~Hz}\right), 7.69(2 \mathrm{H}, \mathrm{d}, J=$ $7.84 \mathrm{~Hz}), 6.57(1 \mathrm{H}, \mathrm{t}, J=7.68 \mathrm{~Hz}), 6.93(1 \mathrm{H}, \mathrm{s}), 6.83(2 \mathrm{H}, \mathrm{dd}$, $\left.J_{1}=9.76, J_{2}=7.80 \mathrm{~Hz}\right), 5.97\left(2 \mathrm{H}, \mathrm{s},-\mathrm{OCH}_{2} \mathrm{O}-\right), 5.04(1 \mathrm{H}, \mathrm{s}$, $\mathrm{NH}), 4.53(2 \mathrm{H}, \mathrm{d}, J=5.40 \mathrm{~Hz}), 4.31\left(1 \mathrm{H}, \mathrm{dt}, J_{1}=8.12, J_{2}=\right.$ $3.84 \mathrm{~Hz}), 3.60(2 \mathrm{H}, \mathrm{s}), 2.93(2 \mathrm{H}, \mathrm{d}, J=9.28 \mathrm{~Hz}), 2.17\left(4 \mathrm{H}, \mathrm{dt}, J_{1}\right.$ $\left.=12.04 \mathrm{~Hz}, J_{2}=9.68 \mathrm{~Hz}\right), 1.94(2 \mathrm{H}, \mathrm{d}, J=11.04 \mathrm{~Hz}) .{ }^{13} \mathrm{C} \mathrm{NMR}$ (400 MHz, DMSO-d6, ppm) $\delta: 155.2,153.2,150.0,147.6,146.6$, $140.8,140.1,134.1,133.6,132.5,131.3,129.9,121.1,119.4,118.8$, 111.7, 108.5, 101.3, 61.1, 55.4, 52.7, 52.5 (2C), 43.4, 31.8 (2C). ESIMS: $m / z 502.3(\mathrm{M}+1), 504.3(\mathrm{M}+3), 506.3(\mathrm{M}+5), 524.4(\mathrm{M}$ $+\mathrm{Na}$ ). $\mathrm{C}_{26} \mathrm{H}_{24} \mathrm{ClN}_{7} \mathrm{O}_{2}$ (501.17).

$N-(B e n z o[d][1,3]$ dioxol-5-ylmethyl)-2-chloro-9-(1-(4-methoxybenzyl)piperidin-4-yl)-9H-purin-6-amine (7b10). Recrystallized from EA/PE as a white crystal, yield 59.4\%, mp: 182$185^{\circ} \mathrm{C} .{ }^{1} \mathrm{H}$ NMR $(400 \mathrm{MHz}, \mathrm{DMSO}-\mathrm{d} 6, \mathrm{ppm}) \delta: 8.30(1 \mathrm{H}, \mathrm{s})$, $7.24(2 \mathrm{H}, \mathrm{d}, J=8.52 \mathrm{~Hz}), 6.90(3 \mathrm{H}, \mathrm{t}, J=6.92 \mathrm{~Hz}), 6.83(2 \mathrm{H}$, $\left.\mathrm{dd}, J_{1}=7.52 \mathrm{~Hz}, J_{2}=3.68 \mathrm{~Hz}\right), 5.97\left(2 \mathrm{H}, \mathrm{s},-\mathrm{OCH}_{2} \mathrm{O}-\right), 5.04$ $(1 \mathrm{H}, \mathrm{s}, \mathrm{NH}), 4.54(2 \mathrm{H}, \mathrm{d}, J=5.92 \mathrm{~Hz}), 4.28\left(1 \mathrm{H}, \mathrm{dt}, J_{1}=8.25, J_{2}\right.$ $=3.32 \mathrm{~Hz}), 3.74(3 \mathrm{H}, \mathrm{s}), 3.44(2 \mathrm{H}, \mathrm{s}), 2.92(2 \mathrm{H}, \mathrm{d}, J=6.24 \mathrm{~Hz})$, $2.07(4 \mathrm{H}, \mathrm{t}, J=7.88 \mathrm{~Hz}), 1.93(2 \mathrm{H}, \mathrm{s}) .{ }^{13} \mathrm{C} \mathrm{NMR}(100 \mathrm{MHz}$, DMSO-d6, ppm) $\delta: 158.8,155.3,153.2,150.0,147.6,146.6,140.1$, $134.5,133.6,130.7,130.5$ (2C), 121.1, 118.9, 114.0 (2C), 108.5, 101.3, 61.7, 55.5, 53.0, 52.4 (2C), 43.4, 31.8 (2C). ESI-MS: $\mathrm{m} / z$ $507.3(\mathrm{M}+1), 509.3(\mathrm{M}+3), 529.3(\mathrm{M}+\mathrm{Na}) . \mathrm{C}_{26} \mathrm{H}_{27} \mathrm{ClN}_{6} \mathrm{O}_{3}$ (506.18).

$N$-(Benzo[d][1,3]dioxol-5-ylmethyl)-2-chloro-9-(1-(2,6-dicholobenzyl)piperidin-4-yl)-9H-purin-6-amine (7b11). Recrystallized from EA/PE as a white crystal, yield: 56.8\%, mp: 199$203^{\circ} \mathrm{C} .{ }^{1} \mathrm{H}$ NMR (400 MHz, DMSO-d6, ppm) $\delta: 8.28(1 \mathrm{H}, \mathrm{s})$, $7.48\left(2 \mathrm{H}, \mathrm{dt}, J_{1}=8.40 \mathrm{~Hz}, J_{2}=0.76 \mathrm{~Hz}\right), 7.34\left(1 \mathrm{H}, \mathrm{dd}, J_{1}=\right.$ $\left.7.54 \mathrm{~Hz}, J_{1}=8.62 \mathrm{~Hz}\right), 6.92(1 \mathrm{H}, \mathrm{s}), 6.83\left(2 \mathrm{H}, \mathrm{dd}, J_{1}=11.74\right.$, $\left.J_{1}=7.9 \mathrm{~Hz}\right), 5.97\left(2 \mathrm{H}, \mathrm{s},-\mathrm{OCH}_{2} \mathrm{O}-\right), 5.04(1 \mathrm{H}, \mathrm{s}, \mathrm{NH}), 4.54$ $(2 \mathrm{H}, \mathrm{d}, J=5.76 \mathrm{~Hz}), 4.54(2 \mathrm{H}, \mathrm{d}, J=6.04 \mathrm{~Hz}), 4.32\left(1 \mathrm{H}, \mathrm{dt}, J_{1}\right.$ $\left.=7.82 \mathrm{~Hz}, J_{2}=4.26 \mathrm{~Hz}\right), 3.74(2 \mathrm{H}, \mathrm{s}), 2.95(2 \mathrm{H}, \mathrm{d}, J=11.6 \mathrm{~Hz})$, $2.39(2 \mathrm{H}, \mathrm{t}, J=1.6 \mathrm{~Hz}), 1.99\left(4 \mathrm{H}, \mathrm{dt}, J_{1}=11.51 \mathrm{~Hz}, J_{2}=9.62 \mathrm{~Hz}\right)$. ${ }^{13} \mathrm{C}$ NMR (100 MHz, DMSO-d6, ppm) $\delta: 155.2,153.2,150.0$, $147.6,146.6,140.1,136.6$ (2C), 134.3, 133.6, 131.9, 130.4, 129.1 (2C), 121.1, 118.9, 108.5, 101.3, 62.3, 56.3, 52.7 (2C), 43.3, 31.8 (2C). ESI-MS: $m / z 547.2(\mathrm{M}+3), 549.2(\mathrm{M}+5), 551.2(\mathrm{M}+$ 7). $\mathrm{C}_{25} \mathrm{H}_{23} \mathrm{Cl}_{3} \mathrm{~N}_{6} \mathrm{O}_{2}$ (544.09).

$N-($ Benzo $[d][1,3]$ dioxol-5-ylmethyl)-2-chloro-9-(1-(2,4,6trimethylbenzyl)piperidin-4-yl)-9H-purin-6-amine (7b12). Recrystallized from EA/PE as a white crystal, yield 63.4\%, mp: $164-167^{\circ} \mathrm{C} .{ }^{1} \mathrm{H}$ NMR (400 MHz, DMSO-d6, ppm) $\delta$ : $8.28(1 \mathrm{H}, \mathrm{s}), 6.92(1 \mathrm{H}, \mathrm{s}), 6.80-6.85(4 \mathrm{H}, \mathrm{m}), 5.96(2 \mathrm{H}, \mathrm{s}$, $\left.-\mathrm{OCH}_{2} \mathrm{O}-\right), 5.03(1 \mathrm{H}, \mathrm{s}, \mathrm{NH}), 4.53(2 \mathrm{H}, \mathrm{d}, J=5.20 \mathrm{~Hz}), 4.29$ $\left(1 \mathrm{H}, \mathrm{dt}, J_{1}=10.28 \mathrm{~Hz}, J_{2}=4.80 \mathrm{~Hz}\right), 3.44(2 \mathrm{H}, \mathrm{s}), 2.86(2 \mathrm{H}, \mathrm{d}$, $J=11.40 \mathrm{~Hz}), 2.32(6 \mathrm{H}, \mathrm{s}), 2.19-2.21(5 \mathrm{H}, \mathrm{m}), 1.94-1.96(4 \mathrm{H}$, m). ${ }^{13} \mathrm{C}$ NMR (100 MHz, DMSO-d6, ppm) $\delta: 155.2,153.2$,
$150.0,147.6,146.6,140.0,138.1,137.9,136.0,133.6,132.2,129.1$ (2C), 121.0, 118.8, 108.5, 101.2, 61.9, 55.4, 52.3 (2C), 43.3, 32.1 (2C), 21.0, 20.2, 19.7. ESI-MS: $m / z 519.4(\mathrm{M}+1), 521.3(\mathrm{M}+$ 3), $523.5(\mathrm{M}+5), 541.4(\mathrm{M}+\mathrm{Na}) . \mathrm{C}_{28} \mathrm{H}_{31} \mathrm{ClN}_{6} \mathrm{O}_{2}$ (518.22).

N-(Benzo[d][1,3]dioxol-5-ylmethyl)-2-chloro-9-(1-(2-fluorobenzyl)piperidin-4-yl)-9H-purin-6-amine (7b13). Recrystallized from EA/PE as a white crystal, yield 64.8\%, mp: 192$195^{\circ}$ C. ${ }^{1} \mathrm{H}$ NMR (400 MHz, DMSO-d6, ppm) $\delta: 8.29(1 \mathrm{H}, \mathrm{s})$, $7.44\left(1 \mathrm{H}, \mathrm{dt}, J_{1}=8.0, J_{2}=1.56 \mathrm{~Hz}\right), 7.33\left(1 \mathrm{H}, \mathrm{dt}, J_{1}=5.64, J_{2}\right.$ $=1.92 \mathrm{~Hz}), 7.18\left(2 \mathrm{H}, \mathrm{dd}, J_{1}=14.2 \mathrm{~Hz}, J_{2}=6.4 \mathrm{~Hz}\right), 6.92(1 \mathrm{H}$, s), $6.85(2 \mathrm{H}, \mathrm{t}, J=7.8 \mathrm{~Hz}), 5.97\left(2 \mathrm{H}, \mathrm{s},-\mathrm{OCH}_{2} \mathrm{O}-\right), 5.04(1 \mathrm{H}$, s, NH), $4.54(2 \mathrm{H}, \mathrm{d}, J=5.76 \mathrm{~Hz}), 4.30\left(1 \mathrm{H}, \mathrm{dt}, J_{1}=11.52 \mathrm{~Hz}\right.$, $\left.J_{2}=4.16 \mathrm{~Hz}\right), 3.59(2 \mathrm{H}, \mathrm{s}), 2.95(2 \mathrm{H}, \mathrm{d}, J=10.2 \mathrm{~Hz}), 2.15(4 \mathrm{H}$, $\left.\mathrm{dt}, J_{1}=23.2 \mathrm{~Hz}, J_{2}=11.72 \mathrm{~Hz}\right), 1.94(2 \mathrm{H}, \mathrm{t}, J=12.88 \mathrm{~Hz}) .{ }^{13} \mathrm{C}$ NMR (100 MHz, DMSO-d6, ppm) $\delta: 162.4,160.0,155.2,153.2$, $149.9,147.6,146.7,140.2$, 133.6, 132.1, 129.6, 125.2, 124.6, 121.1, 118.9, 115.7, 108.5, 101.3, 54.9, 52.8, 52.4 (2C), 43.4, 31.8 (2C). ESI-MS: $m / z 495.3(\mathrm{M}+1), 497.4(\mathrm{M}+3), 517.4(\mathrm{M}+\mathrm{Na})$. $\mathrm{C}_{25} \mathrm{H}_{24} \mathrm{ClFN}_{6} \mathrm{O}_{2}$ (494.16).

4.2. Acetylcholinesterase Inhibition Assay. The ability of derivatives 7a1-7a13 and 7b1-7b13 to inhibit human acetylcholinesterase (hAChE) (Sigma-Aldrich, USA) was examined using the 5,5'-dithiobis-(2-nitrobenzoic acid) (DTNB) method (to generate a yellow chromophore (5-mercapto2-nitrobenzoic acid) detectable at the $405-412 \mathrm{~nm}$ range) with the acetylcholinesterase assay kit (Keygen, China). The assay was carried out as a previously described protocol [10] using donepezil as controls $(n=4)$. Stock solutions of test compounds were dissolved in a minimum volume of DMSO (1\%) and were diluted using saline. In 96 -well plates, $50 \mu \mathrm{L}$ of AChE $(0.22 \mathrm{U} / \mathrm{mL}$ diluted using saline) was incubated with $10 \mu \mathrm{L}$ of various concentrations of test compounds $(1.0,10.0$, $100 \mu \mathrm{M})$ at room temperature for $10 \mathrm{~min}$ followed by the addition of relative agents according to the kit instruction. The absorbance was measured at a wavelength of $405 \mathrm{~nm}$ with Thermo MK3 microplate reader. Percent inhibition was calculated by the comparison of compound-treated to various control incubations.

\section{Conflict of Interests}

The authors declare no conflict of interests.

\section{Acknowledgments}

The financial support from the National Natural Science Foundation of China (NSFC no. 81102320, no. 81273354), Key Project of NSFC for International Cooperation (no. 30910103908), the Natural Science Foundation of Shandong Province (ZR2009CM016), and China Postdoctoral Science Foundation funded project (no. 20100481282, 2012T50584) is gratefully acknowledged.

\section{References}

[1] A. Enz, R. Amstutz, H. Boddeke, G. Gmelin, and J. Malanowski, "Brain selective inhibition of acetylcholinesterase: a novel 
approach to therapy for Alzheimer's disease," Progress in Brain Research, vol. 98, pp. 431-438, 1993.

[2] G. R. Proctor and A. L. Harvey, "Synthesis of tacrine analogues and their structure-activity relationships," Current Medicinal Chemistry, vol. 7, no. 3, pp. 295-302, 2000.

[3] H. Sugimoto, Y. Iimura, Y. Yamanishi, and K. Yamatsu, "Synthesis and structure-activity relationships of acetylcholinesterase inhibitors: 1-benzyl-4-[(5,6-dimethoxy-1-oxoindan-2yl)methyl]piperidine hydrochloride and related compounds," Journal of Medicinal Chemistry, vol. 38, no. 24, pp. 4821-4829, 1995.

[4] D. L. Bai, X. C. Tang, and X. C. He, "Huperzine A, a potential therapeutic agent for treatment of Alzheimer's disease," Current Medicinal Chemistry, vol. 7, no. 3, pp. 355-374, 2000.

[5] J. Winkler, L. J. Thal, F. H. Gage, and L. J. Fisher, "Cholinergic strategies for Alzheimer's disease," Journal of Molecular Medicine, vol. 76, no. 8, pp. 555-567, 1998.

[6] A. Musiał, M. Bajda, and B. Malawska, "Recent developments in cholinesterases inhibitors for Alzheimer's disease treatment," Current Medicinal Chemistry, vol. 14, no. 25, pp. 2654-2679, 2007.

[7] T. Mohamed and P. P. Rao, "Design, synthesis and evaluation of 2,4-disubstituted pyrimidines as cholinesterase inhibitors," Bioorganic \& Medicinal Chemistry Letters, vol. 20, no. 12, pp. 3606-3609, 2010.

[8] T. Mohamed, X. Zhao, L. K. Habib, J. Yang, and P. P. Rao, "Design, synthesis and structure-activity relationship (SAR) studies of 2,4-disubstituted pyrimidine derivatives: dual activity as cholinesterase and A $\beta$-aggregationinhibitors," Bioorganic \& Medicinal Chemistry Letters, vol. 19, no. 7, pp. 2269-2281, 2011.

[9] T. Mohamed, J. C. Yeung, and P. P. Rao, "Development of 2-substituted-N-(naphth-1-ylmethyl) and N-benzhydrylpyrimidin-4-amines as dual cholinesterase and $\mathrm{A} \beta$-aggregation inhibitors: synthesis and biological evaluation," Bioorganic \& Medicinal Chemistry Letters, vol. 21, pp. 5881-5887, 2011.

[10] T. Mohamed, J. C. Yeung, M. S. Vasefi, M. A. Beazely, and P. P. Rao, "Development and evaluation of multifunctional agents for potential treatment of Alzheimer's disease: application to a pyrimidine-2,4-diamine template," Bioorganic \& Medicinal Chemistry Letters, vol. 22, no. 14, pp. 4707-4712, 2012.

[11] P. V. Reddy, N. G. Nair, M. A. Smith, and W. Kudo, "Purinebased triazoles," WO2012051296A2.

[12] J. J. Cui, M. Tran-Dubé, H. Shen et al., "Structure based drug design of crizotinib (PF-02341066), a potent and selective dual inhibitor of mesenchymal-epithelial transition factor (c-MET) kinase and anaplastic lymphoma kinase (ALK)," Journal of Medicinal Chemistry, vol. 54, no. 18, pp. 6342-6363, 2011. 

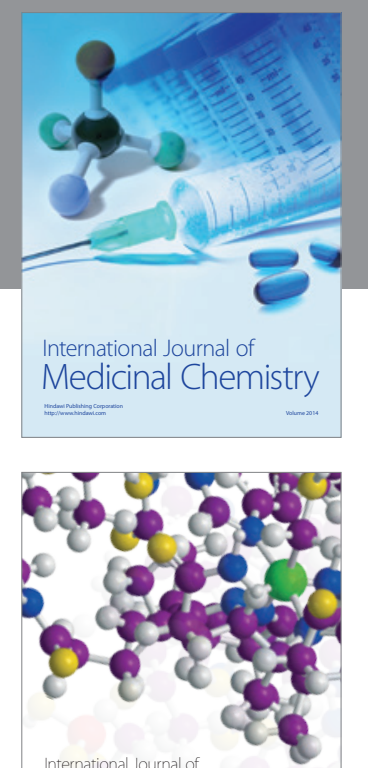

\section{Carbohydrate} Chemistry

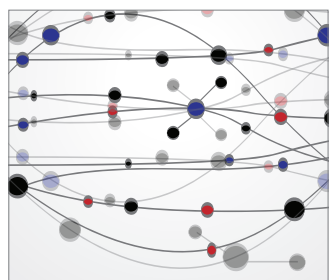

The Scientific World Journal
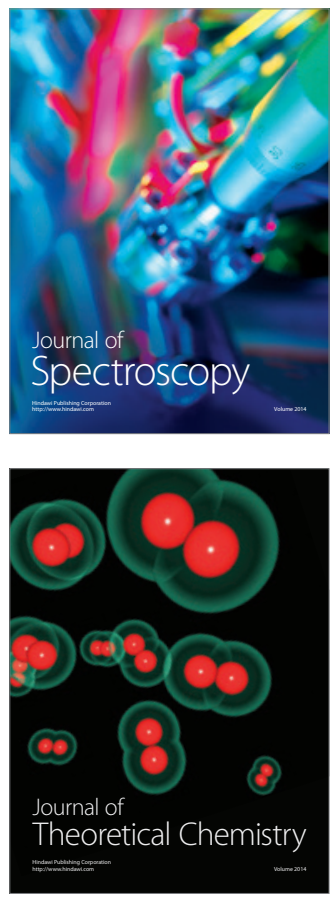
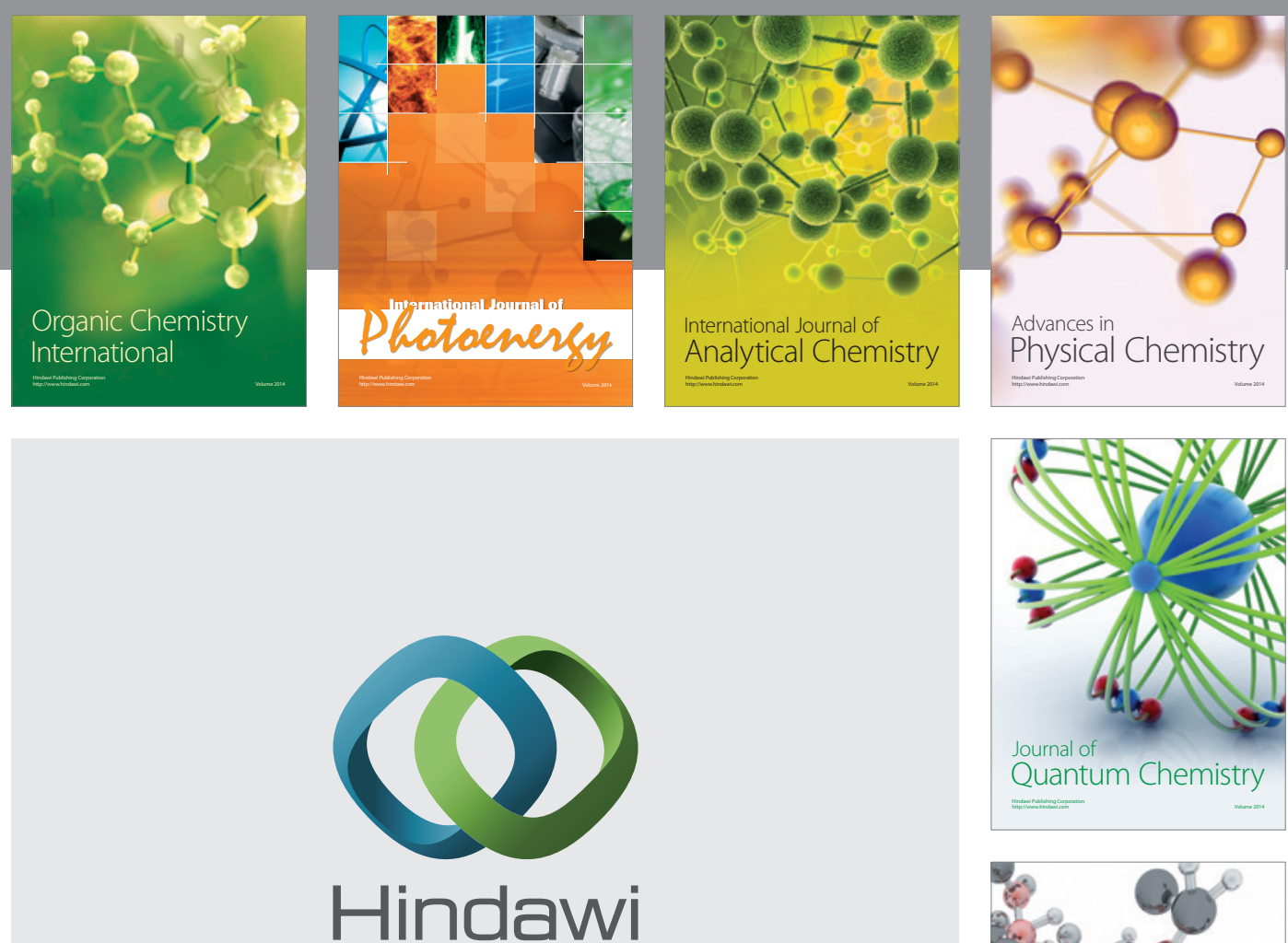

Submit your manuscripts at

http://www.hindawi.com

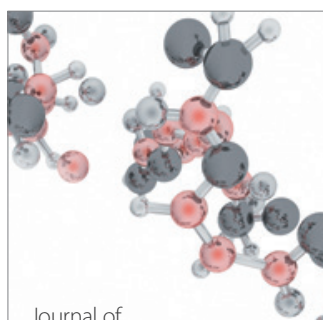

Analytical Methods

in Chemistry

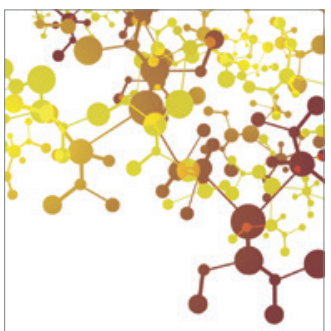

Journal of

Applied Chemistry

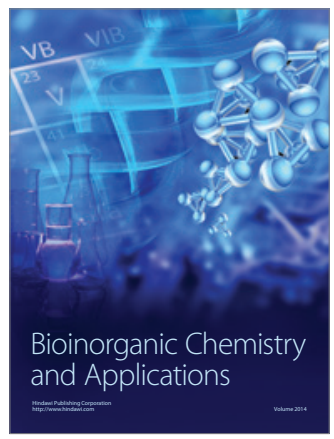

Inorganic Chemistry
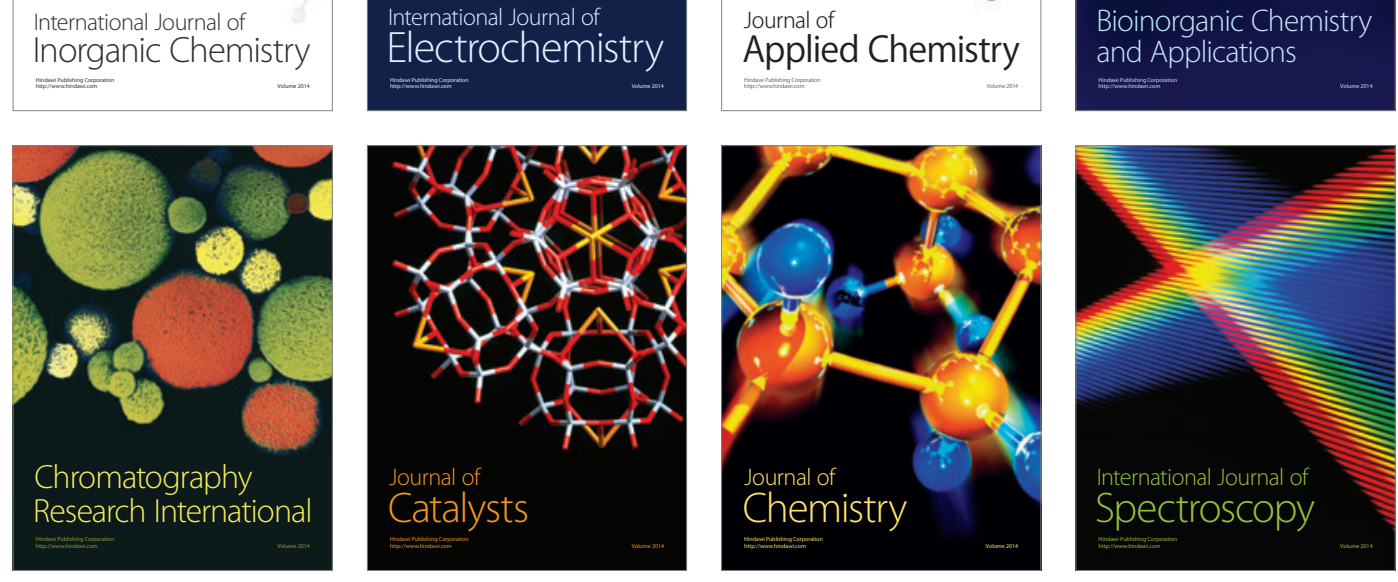